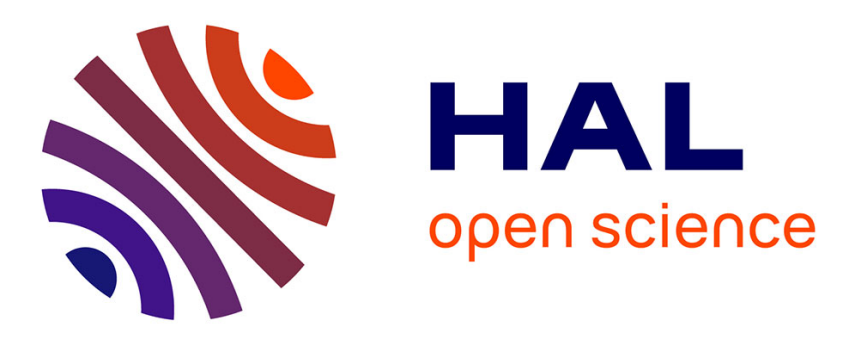

\title{
Elevated prolactin redirects secretory vesicle traffic in rabbit lacrimal acinar cells
}

\author{
Yanru Wang, Christopher T. Chui, Tamako Nakamura, Ameae M. Walker, \\ Barbara B. Petridou, Melvin D. Trousdale, Sarah F. Hamm-Alvarez, Joel E. \\ Schechter, Austin K. Mircheff
}

\section{To cite this version:}

Yanru Wang, Christopher T. Chui, Tamako Nakamura, Ameae M. Walker, Barbara B. Petridou, et al.. Elevated prolactin redirects secretory vesicle traffic in rabbit lacrimal acinar cells. AJP - Endocrinology and Metabolism, 2007, 292 (4), pp.E1122-E1134. 10.1152/ajpendo.00381.2006 . hal-02655884

\section{HAL Id: hal-02655884 \\ https://hal.inrae.fr/hal-02655884}

Submitted on 29 May 2020

HAL is a multi-disciplinary open access archive for the deposit and dissemination of scientific research documents, whether they are published or not. The documents may come from teaching and research institutions in France or abroad, or from public or private research centers.
L'archive ouverte pluridisciplinaire HAL, est destinée au dépôt et à la diffusion de documents scientifiques de niveau recherche, publiés ou non, émanant des établissements d'enseignement et de recherche français ou étrangers, des laboratoires publics ou privés. 


\section{Yanru Wang, Christopher T. Chiu, Tamako Nakamura, Ameae M. Walker, Barbara Petridou, Melvin D. Trousdale, Sarah F. Hamm-Alvarez, Joel E. Schechter and Austin K. Mircheff}

Am J Physiol Endocrinol Metab 292:1122-1134, 2007. First published Dec 12, 2006;

doi:10.1152/ajpendo.00381.2006

You might find this additional information useful...

Supplemental material for this article can be found at: http://ajpendo.physiology.org/cgi/content/full/00381.2006/DC1

This article cites 48 articles, 21 of which you can access free at: http://ajpendo.physiology.org/cgi/content/full/292/4/E1122\#BIBL

This article has been cited by 1 other HighWire hosted article:

Cytopathology and Exocrine Dysfunction Induced in Ex Vivo Rabbit Lacrimal Gland Acinar Cell Models by Chronic Exposure to Histamine or Serotonin

M. L. McDonald, Y. Wang, S. Selvam, T. Nakamura, R. H. Chow, J. E. Schechter, S. C. Yiu and A. K. Mircheff

Invest. Ophthalmol. Vis. Sci., July 1, 2009; 50 (7): 3164-3175.

[Abstract] [Full Text] [PDF]

Updated information and services including high-resolution figures, can be found at:

http://ajpendo.physiology.org/cgi/content/full/292/4/E1122

Additional material and information about AJP - Endocrinology and Metabolism can be found at: http://www.the-aps.org/publications/ajpendo

This information is current as of September 2, 2010 . 


\title{
Elevated prolactin redirects secretory vesicle traffic in rabbit lacrimal acinar cells
}

\author{
Yanru Wang, ${ }^{1}$ Christopher T. Chiu, ${ }^{1}$ Tamako Nakamura, ${ }^{1}$ Ameae M. Walker, ${ }^{2}$ Barbara Petridou, ${ }^{3}$ \\ Melvin D. Trousdale, ${ }^{4}$ Sarah F. Hamm-Alvarez, ${ }^{4,5}$ Joel E. Schechter, ${ }^{6}$ and Austin K. Mircheff ${ }^{1,4}$ \\ ${ }^{1}$ Department of Physiology and Biophysics, Keck School of Medicine, University of Southern California, Los Angeles; \\ ${ }^{2}$ Division of Biomedical Sciences, University of California, Riverside, California; ${ }^{3}$ Unité Génomique et Physiologie \\ de la Lactation, Institut National de Recherche Agronomique, Jouy-en-Josas, France; ${ }^{4}$ Department of Ophthalmology, \\ Keck School of Medicine; ${ }^{5}$ Department of Pharmaceutical Sciences, School of Pharmacy; and ${ }^{6}$ Department of \\ Cell and Neurobiology, Keck School of Medicine, University of Southern California, Los Angeles, California
}

Submitted 31 July 2006; accepted in final form 1 December 2006

\begin{abstract}
Wang Y, Chiu CT, Nakamura T, Walker AM, Petridou B, Trousdale MD, Hamm-Alvarez SF, Schechter JE, Mircheff AK. Elevated prolactin redirects secretory vesicle traffic in rabbit lacrimal acinar cells. Am J Physiol Endocrinol Metab 292: E1122-E1134, 2007. First published December 12, 2006; doi:10.1152/ajpendo.00381.2006.-During pregnancy, lymphocytes infiltrating the rabbit lacrimal gland disperse to the interacinar space from their normal focal concentrations, basal fluid secretion decreases, pilocarpine-induced fluid secretion increases, and stimulated fluid protein concentration decreases. Ductal epithelial cell prolactin (PRL) content increases and redistributes from the apical to the basal-lateral cytoplasm. A replication-incompetent adenovirus vector for rabbit PRL (AdPRL) was used to test the hypothesis that increased intracrine/autocrine PRL signaling alters secretory protein traffic in an ex vivo lacrimal acinar cell model. AdPRL had no discernable influence on microtubules or actin microfilaments or their responses to carbachol $(\mathrm{CCh})$. Endogenous and transduced PRLs exhibited similar, nonpolarized, punctate distributions. Cells secreted PRL consititutively and at increased rates in response to $\mathrm{CCh}$. In contrast, constitutive secretion of $\beta$-hexosaminidase was negligible, suggesting that the constitutive pathway for PRL is relatively inaccessible to typical secretory proteins. AdPRL had no significant effect on total secretion of $\beta$-hexosaminidase or syncollingreen fluorescent protein (GFP), a chimeric secretory protein construct. However, it reversed the polarized distributions of vesicles containing rab3D and syncollin-GFP. Live-cell imaging indicated that AdPRL redirected CCh-dependent syncollin-GFP exocytosis from the apical plasma membrane to the basal-lateral membrane. Elevated concentrations of exogenous rabbit PRL in the ambient medium elicited similar changes. These observations suggest that elevated PRL, as occurs in the physiological hyperprolactinemia of pregnancy, induces lacrimal epithelial cells to express a mixed exocrine/endocrine phenotype that secretes fluid to the acinus-duct lumen but secretes proteins to the underlying tissue space. This phenotype may contribute to the pregnancy-associated immunoarchitecture.
\end{abstract}

ocular surface; mucosal immunity; pregnancy; Sjögren's syndrome

THE OCULAR SURFACE SYSTEM maintains a thin fluid film that comprises an external milieu necessary for optimal homeostasis of its mucosal tissues and of the cornea. Disruptions of ocular surface homeostasis frequently elicit sensations of dryness, itching, or burning. These symptoms may be associated with immune system diseases, such as Sjögren's syndrome and graft vs. host disease, but most cases occur without the typical

Address for reprint requests and other correspondence: A. K. Mircheff, Dept. of Physiology \& Biophysics, Keck School of Medicine, Univ. of Southern California, 1333 San Pablo St., MMR 626, Los Angeles, CA 90033 (email: amirchef@usc.edu). signs of autoimmune disease. They occur more frequently in women than men and are often associated with altered states of the systemic hormonal milieu: perimenopause, postmenopause, pregnancy, lactation, oral contraceptive use (39), and estrogen or estrogen-progesterone replacement therapy (35, 36). Among men, the frequency increases with age (8).

Aging in men is accompanied by gradual decreases in gonadal and adrenal production of androgens. The physiological states associated with altered ocular surface system homeostasis in women share one well-known common denominator, a decrease in the amount of testosterone that is bioavailable, i.e., not sequestered by the sex hormone-binding globulin $(27,45)$. The lacrimal glands secrete most of the electrolytes, water, and other factors that normally comprise the aqueous phase of the ocular surface fluid, and studies addressing the roles testosterone may play in lacrimal gland physiology have produced evidence that testosterone and its more active metabolite, dihydrotestosterone, influence the lacrimal gland's structure (7), functional status $(1,2)$, abilities to express the polymeric immunoglobulin A receptor (pIgR) and secrete $\operatorname{IgA}$, and ability to suppress local autoimmune activation (40).

Prolactin (PRL) is another hormone involved in reproductive physiology that appears to exert important influences on the lacrimal gland and ocular surface system. Although reference values (20) for serum prolactin do not differ very markedly between men $(0-5 \mathrm{ng} / \mathrm{ml})$ and women $(0-20 \mathrm{ng} / \mathrm{ml})$, there is considerable variation among individuals, and among women increasing levels of serum PRL correlate strongly with several different measures of decreased ocular surface fluid function independently of pre- or postmenopausal status or use of hormone replacement therapy (24). Serum PRL levels increase during pregnancy and remain elevated during lactation, and the pregnant rabbit has been studied as a naturally occurring model of physiological hyperprolactinemia. The lacrimal gland undergoes striking immunoarchitectural (37) and functional changes (9). The small periductal and perivenular accumulations of lymphocytes typically found in the normal gland decrease in frequency and size, whereas increased numbers of lymphocytes populate the interacinar space. Rates of fluid production by cannulated glands under basal conditions decrease significantly (9), as do Schirmer's test scores and tear breakup times (10). These indicators of decreased lacrimal

\footnotetext{
The costs of publication of this article were defrayed in part by the payment of page charges. The article must therefore be hereby marked "advertisement" in accordance with 18 U.S.C. Section 1734 solely to indicate this fact.
} 
function are associated with an increased frequency of positive rose Bengal staining tests. Although the amount of fluid the cannulated glands produce in response to pilocarpine stimulation increases, the concentration of protein in pilocarpineinduced fluid decreases (9).

There is reason to predict that PRL influences lacrimal immunoarchitecture and secretory function by acting as a hormone, an intracrine/autocrine mediator, and a paracrine mediator. Frey et al. (11) first reported that human lacrimal glands and tears contain PRL-like immunoreactivity. Subsequent studies using oligonucleotide probes for in situ, dot blot, and Northern blot hybridizations indicate that epithelial cells in rat (28) and rabbit $(16,47)$ lacrimal glands express PRL mRNA. Western blot analyses detect a PRL-immunoreactive protein at $23 \mathrm{kDa}$, the molecular mass of pituitary PRL, in lacrimal gland lysates. Viewed at the light microscope level, PRL-like immunoreactivity appears to be abundant in ductal epithelial cells and also present in acinar cells (37). During pregnancy, its abundance in both acinar and ductal cells increases markedly, and its cytoplasmic distribution changes dramatically. In nonpregnant animals it is concentrated primarily in the apical cytoplasm, consistent with secretion into the nascent lacrimal fluid; in term-pregnant animals it exhibits either a bipolar or a basal-laterally polarized distribution consistent with secretion to the underlying tissue space and a role as an autocrine and paracrine mediator.

The work described herein addressed the question of whether increases in lacrimal gland PRL content exert autocrine/intracrine influences on the secretory functions of lacrimal epithelial cells that might account for the functional changes that occur in pregnancy. A replication-deficient adenovirus vector for rabbit PRL (AdPRL) was constructed and evaluated for effects on secretion of $\beta$-hexosaminidase and a chimeric syncollin-green fluorescent protein (GFP) construct, on cytoplasmic organization, and on secretory protein traffic. The observations indicate that PRL overexpression reorients the classical regulated pathway for protein secretion such that the normal apically-polarized distribution of secretory vesicles is reversed and secretory vesicles are mobilized to the basallateral, rather than apical, membrane in response to cholinergic stimulation.

\section{MATERIALS AND METHODS}

Reagents. Carbamylcholine [carbachol (CCh)], rhodamine-phalloidin, goat anti-mouse secondary antibody conjugated to FITC, and the protease inhibitors pepstatin A, $N$-tosyl-L-phenylalanine chloromethyl ketone, leupeptin, $N$ - $\alpha$ - $p$-tosyl-L-lysine chloromethyl ketone, $N$ - $\alpha-p$ tosyl-L-arginine methyl ester, and phenylmethylsulfonyl fluoride were purchased from Sigma Chemical (St. Louis, MO). Matrigel was from Collaborative Biochemicals (Bedford, MA). Hepato Stim culture medium (HSM) was obtained from Becton Dickinson (Bedford, MA). HyQ Ham's F-12 culture medium was from HyClone Laboratories (Logan, UT). DMEM was from Mediatech (Herndon, VA). Other cell culture reagents were from Life Technologies. Matrisperse Cell Release Solution was purchased from Becton Dickinson (Franklin Lakes, NJ). RNeasy Mini Kit was from Qiagen (Valencia, CA). HighCapacity cDNA Archive kit was from Applied Biosystems (Foster City, CA). Adeno-X Expression System was from BD Clontech (Palo Alto, CA). Vent DNA polymerase and all restriction endonucleases were from New England BioLabs (Beverly, MA).

Guinea pig anti-rabbit PRL antibody was purchased from Dr. Albert F. Parlow of the National Hormone and Peptide Program
(Torrance, CA). Normal guinea pig serum was from Antibodies (Davis, CA). The monoclonal antibody to $\alpha$-tubulin was from Sigma Chemical. Mouse anti-p150 Glued antibody was from Transduction Laboratories (Lexington, KY). Rabbit polyclonal antibody to GFP was from Novus Biologicals (Littleton, CO). Polyclonal antibody to rab3D was generated in rabbits against recombinant rab3D produced in $E$. coli (Antibodies) and purified by chromatography over protein A/G-agarose.

IRDye 800-conjugated secondary antibodies (goat anti-rabbit, goat anti-mouse, and goat anti-guinea pig) were purchased from Rockland Immunochemicals (Gilbertsville, PA). ProLong antifade mounting media, goat anti-rabbit secondary antibody conjugated to Alexa fluor 568 , donkey anti-sheep secondary antibody conjugated to Alexa fluor 680, and Alexa fluor 647-phalloidin were from Molecular Probes (Eugene, OR). Donkey anti-guinea pig IgG conjugated with FITC and with rhodamine were from Jackson ImmunoResearch Laboratories, (West Grove, PA). Paraformaldehyde was from Polysciences (Warrington, PA). All other chemicals were reagent grade and were obtained from standard suppliers.

Generation of vectors. The cDNA for rabbit PRL, which includes the intact nucleotide code for the signal peptide (MDSKWSRRTGSLLLLLVSNLLLCKSTASL), has been cloned and described by Gabou et al. (12). The recombinant adenoviral vector, AdPRL, was constructed with the Adeno-X Expression System. Briefly, the PRL cDNA (GenBank accession no. U27199) was subjected to polymerase chain reaction (PCR) to insert $\mathrm{NheI}$ and $\mathrm{XbaI}$ restriction enzyme sites. PCR was performed using Vent DNA polymerase and the following parameters: denaturation at $95^{\circ} \mathrm{C}$ for $30 \mathrm{~s}$, annealing at $60^{\circ} \mathrm{C}$ for $1 \mathrm{~min}$, and extension at $72^{\circ} \mathrm{C}$ for $2 \mathrm{~min}$. Sense and antisense primers were designed to anneal to the $5^{\prime}$ and $3^{\prime}$ ends of the rabbit PRL open reading frame sequence as published in GenBank: sense primer, 5' TCCGCTAGCGCCACCATGGACAGCAAGTGGTCACGGAGG-3'; antisense primer, 5'-ACGTCTAGATTACCAATTGCTGTCATAGATGAT-3'.

The amplified fragments were then cloned into the shuttle plasmid, pShuttle, which contains a cytomegalovirus (CMV) promoter and bovine growth hormone polyA with I-CeuI and PI-SceI homing endonuclease sites encompassing the mammalian expression cassettes to form pShuttle-PRL. The expression cassettes containing rabbit PRL open reading frame were excised from the pShuttle-PRL by I-CeuI and PI-SceI and ligated to Adeno-X Viral DNA (the adenoviral genome) to form the recombinant AdPRL. AdSyncollin-GFP was generated as described previously (22).

AdGFP and AdLacZ were constructed as previously described (41). Briefly, the shuttle plasmid, pAdTrack, which contains a CMVdriven GFP marker gene and two arms of homology to the left and right ends of the Ad5 genome, was recombined in the recombinogenic E. coli BJ5183 strain, along with a large $30-\mathrm{kb}$ supercoiled plasmid, pAdEasy, which contains an adenoviral genome recreating the replication-deficient Ad genome. The selected transformants were retransformed into the more stable DH10 strain to prevent further recombination events. A different shuttle plasmid, pShuttle, was used to generate Ad-expressing $\beta$-galactosidase (LacZ) by homologous recombination as described. AdLacZ contains an expression cassette including the $E$. coli $\beta$-galactosidase gene with a eukaryotic nuclear translocation signal under the transcriptional control of the CMV promoter. All virus stocks were produced in 293 cells expressing the E1A and E1B proteins, which support the replication of the E1defective adenoviral mutants, followed by amplification and purification of the harvested virus by cesium chloride ultracentrifugation and dialysis. The titer of the purified viral stocks was determined using plaque assays $(\mathrm{pfu} / \mathrm{ml})$. Transduction efficiency in reconstituted lacrimal acini was determined by immunofluorescent staining with antirabbit prolactin antibody (for detection of AdPRL), flow cytometry and fluorescence microscopy (for detection of AdGFP and AdSyncollin-GFP), or colorimetric production with X-Gal as substrate (for detection of AdLacZ). 
Cell isolation and culture. Female New Zealand white rabbits weighing $\sim 2$ or $4 \mathrm{~kg}$ were obtained from Irish Farms (Norco, CA). They were used in accordance with the Guiding Principles for the Use of Animals in Research, with a protocol approved by the Institutional Animal Care and Use Committee. Lacrimal gland acinar cells were isolated and cultured as described previously $(13,14,38)$. For biochemical and functional studies the lacrimal acinar cells from 4-kg rabbits were resuspended at $4^{\circ} \mathrm{C}$ in $\mathrm{HSM}$ containing $10 \% \mathrm{FBS}, 5$ $\mathrm{ng} / \mathrm{ml} \mathrm{EGF}$, and $1 \mathrm{mg} / \mathrm{ml}$ Matrigel and then warmed to $37^{\circ} \mathrm{C}$ and incubated for $1 \mathrm{~h}$ to promote formation of Matrigel particles, referred to as "rafts" (38). For immunofluorescence staining, cells from 2-kg rabbits were seeded onto $18-\mathrm{mm}$ circular glass coverslips coated with Matrigel and grown in a medium that consisted of 50\% Ham's F-12 and 50\% DMEM supplemented with penicillin, streptomycin, laminin, thyroxine, hydrocortisone, insulin, transferrin, and selenium. For measurement of $\left[{ }^{3} \mathrm{H}\right]$ thymidine incorporation, they were grown in Matrigel-coated 96-well plates. Cells were cultured for 3 or 4 days before analysis. For gene transduction, adenoviral constructs were added to 2-day cultures at a multiplicity of infection (MOI) of 6 $\mathrm{pfu} / \mathrm{cell}$ and incubated at $37^{\circ} \mathrm{C}$ for $1-2 \mathrm{~h}$. Virus was removed by three washes with PBS. Cells were used $24 \mathrm{~h}$ after infection, i.e., on day 3 , for immunofluorescence staining and $48 \mathrm{~h}$ after infection, i.e., on day 4 , for secretion and Western blot studies.

RNA extraction and reverse transcription. Control and AdPRLtransduced cells were harvested on day 3. Total cellular RNA was isolated from freshly harvested cells using an RNeasy Mini Kit with on-column DNase digestion to reduce the possibility of DNA contamination. Then, 5 to $10 \mu \mathrm{g}$ of total RNA were reverse transcribed to cDNA by High-Capacity cDNA Archive kit containing random primers and MultiScribe Reverse Transcriptase according to the manufacturer's instruction.

Real-time PCR. Primers and probes were selected using Primer Expres software (Applied Biosystems) and synthesized by Applied Biosystems. The upstream primer was from exon 1 (5'-GCCGTCAACTGCCAAGTGT- $3^{\prime}$ ), and the downstream primer was selected, spanning the conjunction of putative exon 1 and exon $2\left(5^{\prime}\right.$-ATGAACCCTCTGCCCTGGGTAT-3'). The probe consisted of the oligonucleotide 5'-CGGGATCTGTTTGACCGTGCGG-3', with the 5' reporter dye 6-carboxyfluorescin (FAM) and the $3^{\prime}$ quencher dye 6-carboxytertramethylrhodamine (TAMRA). Real-time PCR analysis was performed with an ABI PRISM 7900 HT Sequence Detection System (Applied Biosystems) using TaqMan universal PCR master mix containing the internal dye, ROX, as a passive reference. The reporter dye (FAM) signal was measured against the ROX signal to normalize for non-PCR-related fluorescence fluctuations. The PCR reaction was processed in a $10-\mu l$ volume with $1 \times$ TaqMan universal PCR master mix, $900 \mathrm{nM}$ forward and reverse primers, $250 \mathrm{nM}$ probe, and $1 \mu \mathrm{l}$ of cDNA template. The cycle threshold $\left(\mathrm{C}_{\mathrm{T}}\right)$ value represented the refraction cycle number at which a positive amplification reaction was measured and was set at 10 times the standard deviation of the mean baseline emission calculated for PCR cycles 3-15. $\mathrm{C}_{\mathrm{T}}$ values of different samples were corrected for differences in the amount of input material based on the housekeeping gene, GAPDH, as an internal control (19).

Confocal fluorescence microscopy. Acinar cells were cultured on Matrigel-coated glass coverslips in 12-well plates. For analysis of the distribution of PRL immunoreactivity in parallel with actin filaments or other intracellular compartments, acinar cells were rinsed with PBS and then either fixed and permeabilized with ethanol at $-20^{\circ} \mathrm{C}$ for 10 min before rehydration in PBS, as previously described (41), or fixed with $4 \%$ paraformaldehyde at room temperature for $15 \mathrm{~min}$ before permeabilization with $0.25 \%$ Triton $\mathrm{X}-100$ at room temperature for 10 min. Samples were blocked with $1 \%$ bovine serum albumin (BSA) and incubated with appropriate primary and FITC-conjugated and/or Alexa fluor 568-conjugated secondary antibodies and Alexa fluor 647or rhodamine-phalloidin. Images from dual-labeled specimens were acquired on a Nikon PCM Confocal System equipped with Argon ion
$(488 \mathrm{~nm})$ and HeNe $(543 \mathrm{~nm})$ lasers attached to a Nikon TE300 Quantum inverted microscope. Images from triple-labeled specimens were acquired on a Zeiss LSM 510 Meta NLO Imaging System equipped with Argon, red HeNe, and green HeNe lasers (Unternehmensberich Mikroskopie; Carl Zeiss Jena, Jena, Germany) using argon ion at $488 \mathrm{~nm}$, red $\mathrm{HeNe}$ at $543 \mathrm{~nm}$, and green HeNe at $633 \mathrm{~nm}$. The immunofluorescence micrographic images were compiled in Adobe Photoshop 7.0 (Adobe Systems, Mountain View, CA).

For live-cell imaging studies, cells were grown on Matrigel-covered, glass-bottomed, round 35-mm dishes (MatTek, Ashland, MA) at a density of $4 \times 10^{6}$ cells per dish. After 2 days they were transduced with AdSyn-GFP, AdSyn-GFP plus AdPRL, or AdSyn-GFP plus AdLacZ, all at a MOI of 6 , for $2 \mathrm{~h}$. Cells were then rinsed and cultured in fresh medium for $16 \mathrm{~h}$ to allow protein expression. Dual transduction efficiency (as indicated by syncollin-GFP expression) ranged from 80 to $90 \%$ in each experiment. On day 3, they were analyzed by time lapse confocal fluorescence and differential interference contrast (DIC) microscopy using a Zeiss LSM 510 Meta NLO Imaging System with Zeiss Multiple Time Series V3.2 and Physiology V3.2 software modules. Live-cell analyses were performed at $37^{\circ} \mathrm{C}$. DIC images and GFP fluorescence were acquired simultaneously using the 488 line of the Argon Laser.

Western blotting. Proteins in the supernatant culture medium were concentrated 10 -fold by centrifugation with $10-\mathrm{kDa}$ cutoff Centricon centrifugal filter devices. Cells were released from Matrigel rafts by incubation with Matrisperse Cell Release Solution for $1 \mathrm{~h}$. on ice. After being washed with PBS, the cells were lysed in RIPA buffer ( $1 \%$ NP-40, $0.5 \%$ sodium deoxycholate, and $0.1 \%$ SDS in PBS) containing protease inhibitor cocktail and passed through a 25-G needle 10 times. Following centrifugation for $10 \mathrm{~min}$ at $13,000 \mathrm{rpm}$ to pellet the cell debris, the supernatants were collected. Aliquots of concentrated supernatant culture medium and cell lysate samples containing equal amounts of total protein were analyzed by SDS polyacrylamide gel electrophoresis and transferred onto nitrocellulose membranes, blocked with Odyssey blocking buffer (LiCor Biosciences) at room temperature for $1 \mathrm{~h}$, and then incubated with the appropriate primary antibody at room temperature for $1-2 \mathrm{~h}$ or at $4^{\circ} \mathrm{C}$ overnight. After five 15-min washes with Tris-buffered saline containing Tween 20 (TBST), the blots were incubated with an appropriate secondary antibody conjugated to IRDye 800 or Alexa fluor 680. After extensive washing with TBST, the blots were scanned using an Odyssey Scanning Infrared Fluorescence Imaging System (LiCor, Lincoln, NE) and quantified using proprietary software supplied by the manufacturer.

Metabolic protein labeling. After incubation in sulfur amino acidfree medium for $30 \mathrm{~min}$, acini were labeled with ${ }^{35} \mathrm{~S}$ translabel $(6.6$ $\mu \mathrm{Ci} / 1,000,000$ cells) in sulfur amino acid-free medium for $1 \mathrm{~h}$ at $37^{\circ} \mathrm{C}$. Acini were lysed, and aliquots containing equivalent amounts of protein from control and transduced cells were analyzed by SDS-PAGE. Gels were treated with DMSO-PPO for visualizing ${ }^{35} \mathrm{~S}$-labeled proteins and stained with Coomassie Brilliant Blue G250 prior to autoradiography for 1-2 days.

Secretion assays. Secretion assays were performed as described previously (29). Cells in Matrigel rafts were washed and resuspended in fresh medium. Some rafts were sedimented at the defined start of the incubation period and others after 20- and 60-min incubations with or without $100 \mu \mathrm{M}$ CCh. Aliquots of supernatant medium were removed for assay of protein content and $\beta$-hexosaminidase activity. All determinations were done with three replicate aliquots, and each incubation was performed with at least three replicate raft samples. Protein was assayed with the Micro BCA Protein Assay Reagent (Pierce), using BSA as standard, and $\beta$-hexosaminidase activity was assayed using methyumbelliferyl- $\beta$-D-glucosaminide as substrate. Both assays were done in 96-well plates, and signals were read with a Tecan GENios Plus UV/Visible/Fluorescence Plate Reader (Phenix Research Products, Hayward CA). For analysis of PRL or syncollinGFP release, 200- $\mu$ l aliquots of supernatant medium were concen- 
A

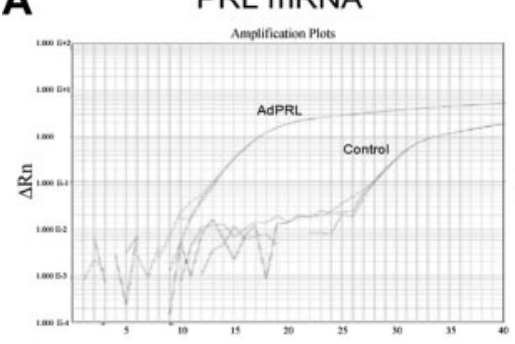

B

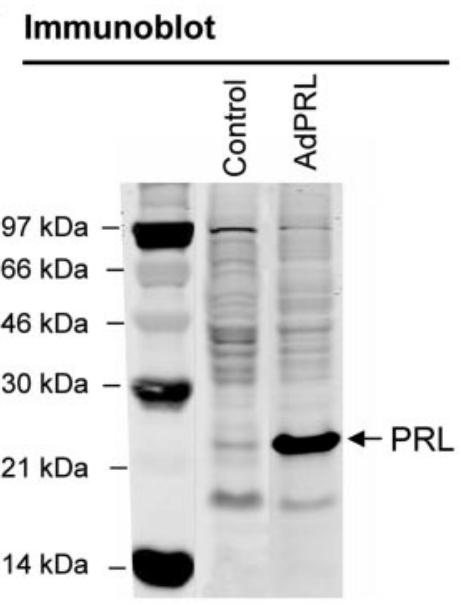

GAPDH mRNA

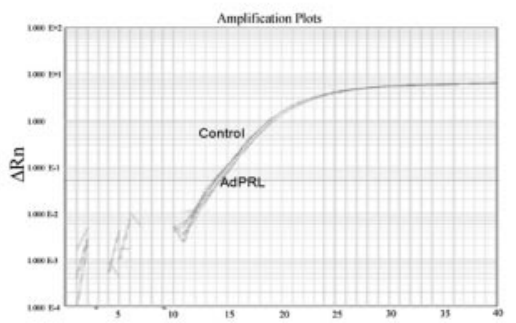

Autoradiogram

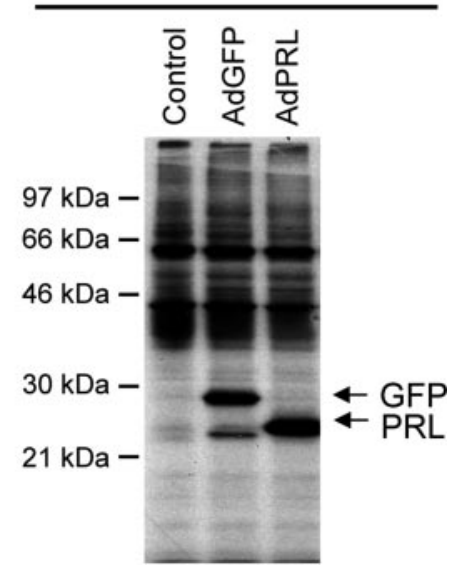

Fig. 1. Prolactin (PRL) expression and adenovirus vector-mediated overexpression in rabbit lacrimal acinar cells. Control and adenovirus vector for rabbit PRL (AdPRL)-transduced rabbit lacrimal acini grown in Matrigel rafts were treated with Matrisperse and then analyzed. Amplification plots of real-time reverse transcriptase-polymerase chain reaction analyses of control and AdPRL-transduced cells showing cycle threshold values for prolactin mRNA and GAPDH mRNA. The analyses confirm that rabbit lacrimal gland acinar cells express PRL message and that the AdPRL vector effectively increases its expression. Left: Western blot probed with guinea pig anti-rabbit prolactin antibody and IRDye 800 -conjugated anti-guinea pig IgG antibodies. The data confirm that nontransduced acinar cells express PRL protein and that transduction with AdPRL increases expression of the protein. Right: autoradiographic detection of newly synthesized proteins. Control, AdGFP-transduced and AdPRL-transduced acini were pulse labeled with $\left.{ }^{35} \mathrm{~S}\right]$ translabel. The autoradiogram shows the spectrum of proteins labeled with ${ }^{35} \mathrm{~S}$ in control and transduced (AdGFP or AdPRL) cells. Banding patterns and intensities were comparable for the 3 samples, with exception of an $\sim 28$-kDa protein in AdGFP lysates, identified as green fluorescent protein (GFP) by Western blotting (data not shown) and an $\sim 23-\mathrm{kDa}$ protein in AdPRL, lysates, identified as PRL. trated on Centricon 10 filters, and syncollin-GFP was detected by Western blotting. Signal intensity was normalized to pellet protein in each sample and expressed as fluorescence intensity per milligram protein.

\section{RESULTS}

PRL $m R N A$ and protein expression in rabbit lacrimal acinar cells. Real-time RT-PCR using primers spanning the intron region between putative exon 1 and exon 2 and a rabbit PRL-specific TaqMan probe detected PRL transcript in primary cultured acinar cells, as shown in Fig. 1A. Probing Western blots of cell lysates with the guinea pig anti-rabbit PRL antibody consistently revealed a $23-\mathrm{kDa}$ immunoreactive protein (Fig. 1B). Specificity of the antibody reaction was confirmed by an absence of labeling with normal guinea pig serum or with antibody that had been prebsorbed with $1 \mu \mathrm{M}$ recombinant rabbit PRL (data not shown).

Adenovirus vector-mediated overexpression of PRL. Lacrimal gland acinar cells are refractory to many gene transfer methods, but several studies $(18,41,49)$ have shown that they can be transduced very efficiently with recombinant adenovirus vectors. Therefore, a replication-deficient recombinant adenovirus vector (AdPRL) containing cDNA for rabbit PRL was constructed. Recombinant adenovirus vectors containing cDNAs for GFP (AdGFP) and $\beta$-galactosidase (AdLacZ) were used as controls. In preliminary experiments these vectors were tested at MOI of 3, 6, and 10 pfu/acinar cell. MOI of 6 gave transduction efficiencies of 80 to $90 \%$ for cells grown in Matrigel rafts and on Matrigel-coated coverslips, and it did not cause significant cell loss. Since efficiency was not increased if MOI was increased to 10, MOI of 6 was utilized for all subsequent experiments. The high transduction efficiency was confirmed by flow cytometric analysis of acinar cells that had been transduced with AdGFP (data not shown). The abundance of PRL transcripts determined by real-time RT-PCR was increased $>14,000$-fold in AdPRL-transduced cells. Correspondingly, the abundance of PRL protein detected by immunofluorescence and Western blotting was significantly increased (Fig. 1). Analysis of ${ }^{35} \mathrm{~S}$ incorporation into newly synthesized protein readily detected the overexpressed GFP and PRL; the analysis also indicated that overall protein synthesis was not otherwise markedly altered by AdGFP or AdPRL (Fig. 1).

Cytoskeletal organization after AdPRL transduction. Labeling of the dense web of actin microfilaments underlying the apical plasma membrane and of the thinner web underlying the basal-lateral membrane by rhodamine-phalloidin provides convenient features for delineating the individual cells in acinar groupings, locations of the acinar lumena, and cellular polarity. Neither AdLacZ nor AdPRL significantly altered actin microfilament organization (Fig. 2). Labeling with anti- $\alpha$-tubulin revealed microtubule arrays that originated from organizing centers in the apical regions and radiated toward the basallateral surfaces. Neither AdLacZ nor AdPRL significantly altered organization of actin microfilaments or microtubule tubules. Stimulation with $100 \mu \mathrm{M}$ CCh markedly altered both cytoskeletal components. The apical actin microfilament web thinned considerably, and the basal-lateral actin cortex became more irregular, making it difficult to discern the lumena or distinguish between apical- and basal-lateral surfaces. Microtubule arrays lost their radial organization and formed bundlelike structures located both within the cytoplasm and at cell 

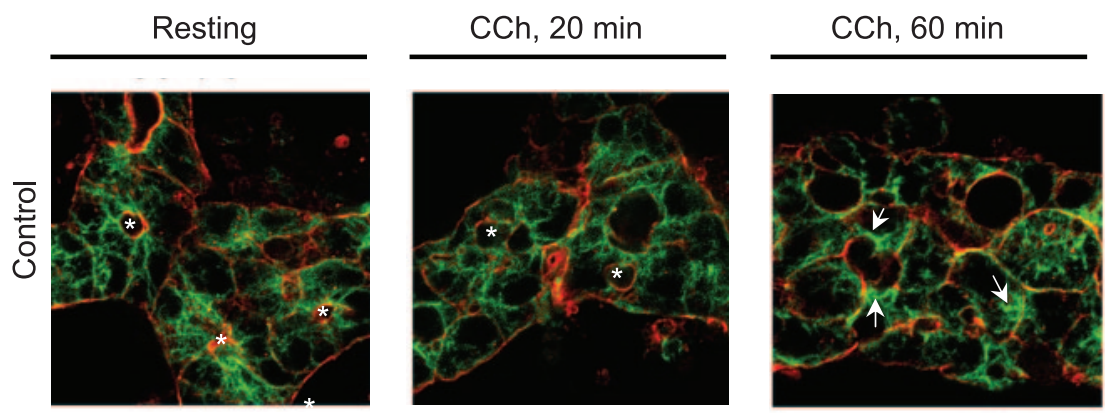

Fig. 2. Microbubule and actin microfilament organization. Control and transduced (AdPRL or AdLacZ) acini were fixed and stained with rhodamine phalloidin to mark actin filaments (red) and with mouse anti- $\alpha$-tubulin antibody and secondary antibody (green) to mark microtubules. Thickening of the actin microfilament network in the terminal web subjacent to the apical plasma membrane outlines the acinar lumina $(*)$. The images reveal no evident alteration of cytoskeletal organization (bar, $10 \mu \mathrm{m}$ ). CCh, carbachol.
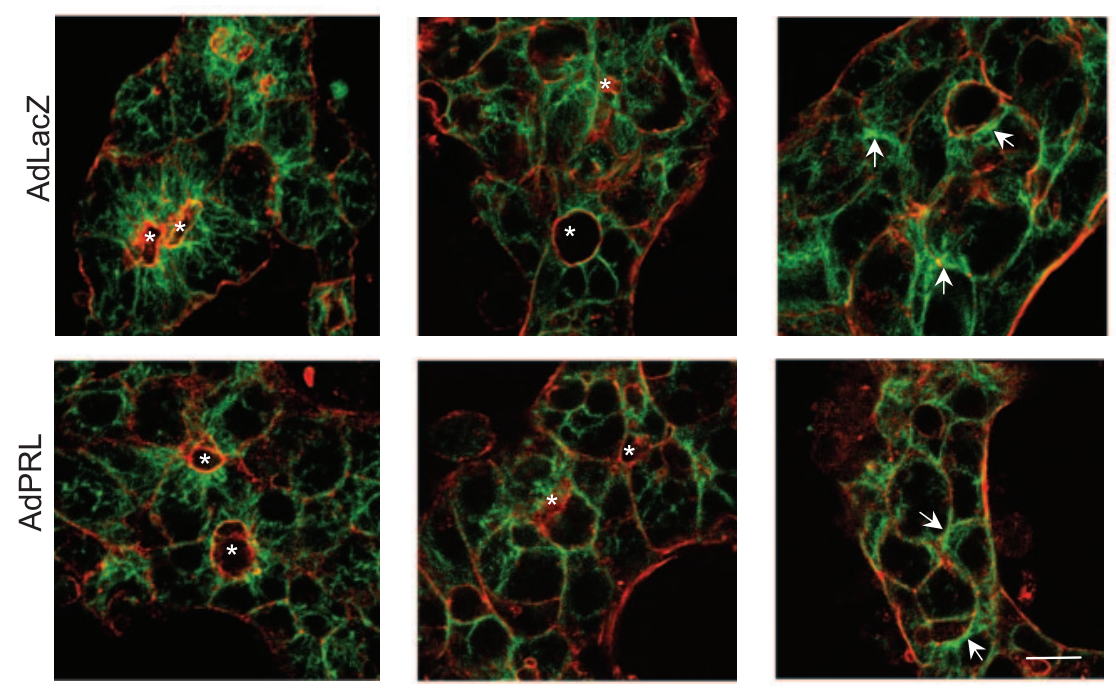

peripheries (arrows in Fig. 2). The CCh-induced changes were evident within $20 \mathrm{~min}$ of stimulation and were more pronounced by $60 \mathrm{~min}$. However, there was no indication that the CCh-induced changes were influenced by transduction with LacZ or AdPRL.

PRL secretion. Previous reports that PRL is present in both lacrimal gland and ocular surface fluid $(11,44)$ suggested that lacrimal PRL secretion might be regulated analogously to secretion of other lacrimal proteins. The immunofluorescence studies illustrated in Fig. 2 and most other experiments reported herein were performed with acinar cells grown on Matrigel-coated coverslips. However, secretion studies were performed with acinar cells grown in Matrigel rafts, and an initial experiment was performed to test whether transduction with AdPRL might cause notable morphological changes in the raft model. As illustrated in Fig. $3 A$, no such changes were apparent.

Western blot analyses of $>10 \mathrm{kDa}$ proteins concentrated from the supernatant medium indicated that nontransduced cells released intact 23-kDa PRL into their ambient media and that stimulation with $100 \mu \mathrm{M}$ CCh increased the rate of PRL secretion. AdPRL-transduced cells also released overexpressed PRL in constitutive- and CCh-dependent fashions (Fig. 3B). Analyses of the time courses of PRL release (Fig. $3 C$ ) indicate that CCh dramatically increased secretion of PRL by AdPRLtransduced cells during the first 20 min of stimulation. However, after $20 \mathrm{~min}$ the rate of secretion subsided, and there was no significant difference between the amounts detected in the media at 20 and $60 \mathrm{~min}$.

The observation that AdPRL-transduced cells secreted PRL even in the absence of $\mathrm{CCh}$ stimulation accords with the hypothesis that PRL leaves the cells by way of both constitutive and regulated pathways. In experiments testing the competing hypothesis that transduction by adenovectors induced a nonspecific leakage of overexpressed proteins, the supernatant media from AdGFP-transduced cells incubated with or without CCh were examined. Little GFP could be detected, and the amount was not significantly influenced by $\mathrm{CCh}$ stimulation (data not shown). Subsequent experiments with another construct, AdSyncollin-GFP (discussed below) also suggested that the adenovirus vectors caused no apparent increase in basal release relative to CCh-induced secretion of AdSyncollin-GFP.

$\beta$-hexosaminidase secretion. In accord with previous studies in our laboratories (43), transduction with AdGFP appeared to cause a modest decrease in CCh-stimulated secretion of $\beta$-hexosaminidase (Fig. 3D). However, in contrast to our initial report that chronic treatment with ovine PRL inhibited $\beta$-hexosaminidase secretion (5), transduction of cells with AdPRL did not significantly change $\beta$-hexosaminidase secretion from the values in nontransduced cells.

In all cases, $\beta$-hexosaminidase secretion, like PRL secretion (Fig. 3, $C$ and $D$ ), decreased markedly after 20 min of stimulation with $\mathrm{CCh}$. This observation might suggest that $\mathrm{CCh}-$ dependent PRL secretion is mediated by the same pathway(s) as CCh-dependent $\beta$-hexosaminidase secretion. On the other hand, when release of PRL is presented in the same units as $\beta$-hexosaminidase, i.e., normalized to the amount released at 20 min in the absence of $\mathrm{CCh}$, it is evident that the basal rate of secretion is larger and the CCh-dependent component of secretion smaller for PRL than for $\beta$-hexosaminidase. These differences would suggest that AdPRL-transduced cells ex- 
A
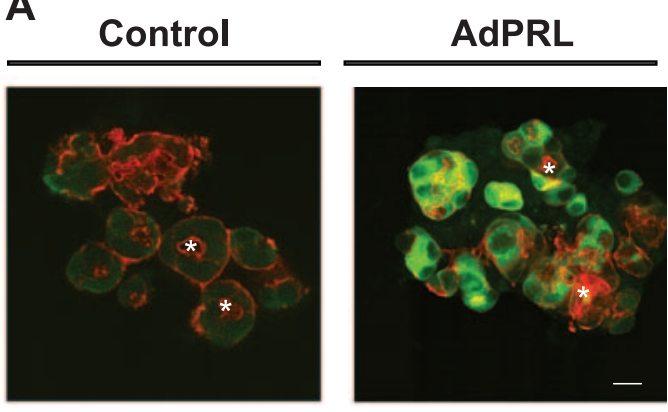

B

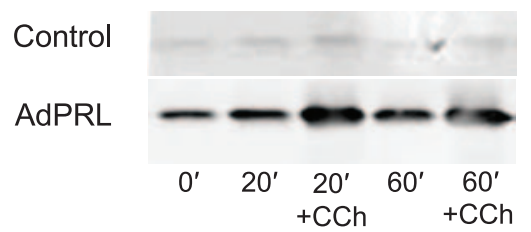

C
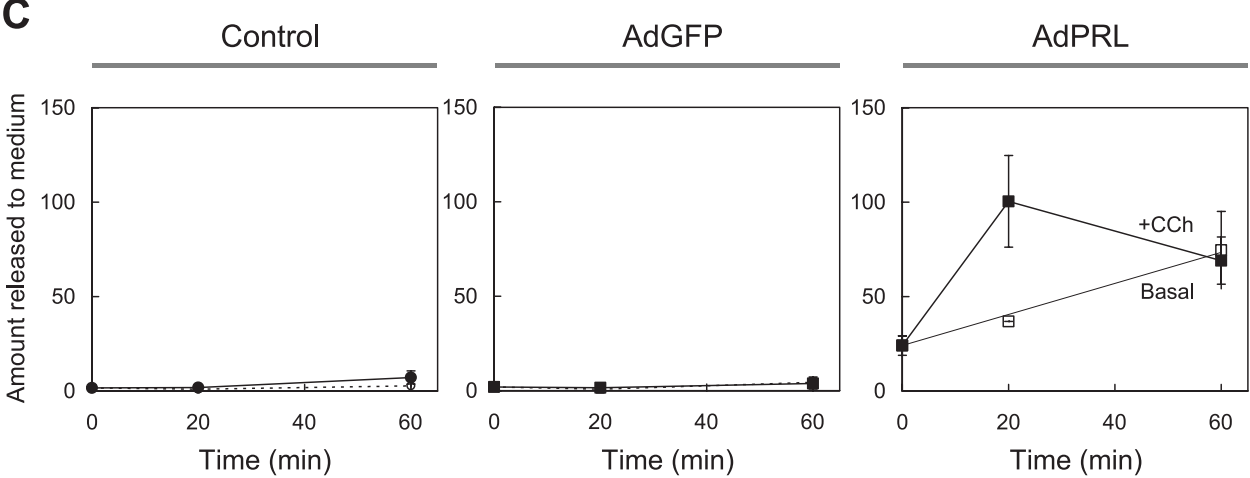

D
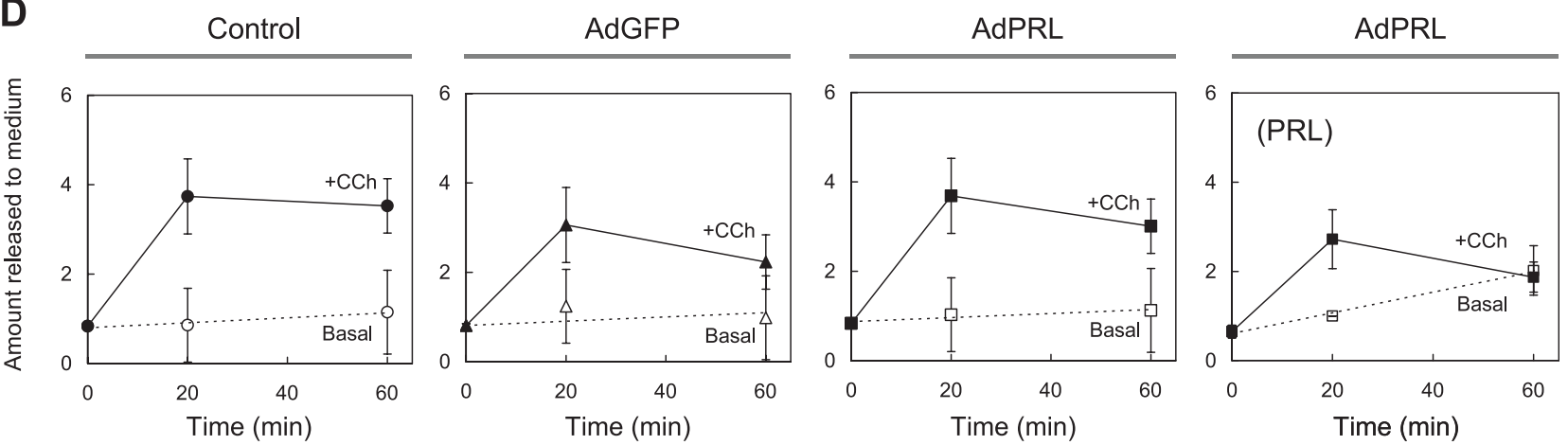

Fig. 3. Secretion of PRL and $\beta$-hexosaminidase. A: staining control and AdPRL-transduced acini in Matrigel rafts for PRL (green) and actin filaments (red) reveals intense immunoreactivity for PRL and no evident effect on morphology after transduction with AdPRL. *Acinar lumena. Bar, $10 \mu \mathrm{m} . \quad B$ : Western blot analyses of supernatant culture media indicate that both control and AdPRL-transduced cells secrete $23 \mathrm{kDa}$ PRL. $C$ : time courses of PRL release into the supernatant culture media suggest that AdPRL-transduced cells secrete PRL by both constitutive and stimulation-dependent pathways. (Values from Western blot analyses were normalized to the value for nontransduced cells incubated for $20 \mathrm{~min}$ in the absence of CCh.) $D$ : time course of $\beta$-hexosaminidase secretion by control, AdGFP-transduced, and AdPRL-transduced acini indicate little time-dependent secretion of $\beta$-hexosaminidase in the absence of CCh stimulation, a slight decrease of secretion by AdGFP transduction, and no difference between nontransduced and AdPRL-transduced cells. Values from assays of $\beta$-hexosaminidase catalytic activity were normalized to the values for cells incubated $20 \mathrm{~min}$ in the absence of CCh. Presentation of data for PRL secretion by AdPRL-transduced cells in these units emphasizes the relatively greater constitutive secretion of PRL and relatively smaller component of PRL secretion that is stimulation dependent.

press a constitutive pathway for secretion of PRL that is either inaccessible, or not so readily accessible, to $\beta$-hexosaminidase.

Intracellular compartmental organization and traffic of PRL. Models of acinar cell membrane traffic include several different membrane compartments that might mediate PRL secretion: 1) classic regulated secretory vesicles, which occupy the apical cytoplasm in resting cells and which fuse with the apical plasma membrane in response to stimulation by $\mathrm{CCh}$ and other agonists; 2) recruitable secretory transport vesicles (RSTV), which arise from the trans-Golgi network (TGN) and fuse with the apical membrane in response to $\mathrm{CCh}$; 3) terminal transcytotic vesicles, which are thought to arise from an apical recycling endosome and fuse with the apical membrane to release the pIgR secretory component and secretory $\operatorname{Ig} \mathrm{A}$; and 4) exocytotic vesicles that arise from the early and recycling endosomes and fuse with the basal-lateral plasma membrane to insert pIgR.

The confocal immunofluorescence micrographs in Fig. $4 B$ reveal similar punctate and occasionally somewhat reticular distributions of PRL, consistent with traffic through a variety of intracellular compartments, in both nontransduced and AdPRL-transduced cells. In an attempt to address the hypothesis that the CCh-dependent component of PRL secretion is mediated by the regulated apical secretory pathway, a possible colocalization of PRL with rab3D, an effector of exocytosis that provides a useful marker for mature merocrine secretory 
A

Fig. 4. $A$ and $B$ : influence of PRL overexpression on distribution of rab3D. Confocal immunofluorescence microscopy of control and AdPRL-transduced cells stained for PRL (green) and rab3D (red) indicates that there was relatively little colocalization of PRL with rab3D (arrows), an effector of the major regulated apical secretory pathway for protein in lacrimal acinar cells. For AdPRL-transduced acini, unconjugated donkey anti-guinea pig antibody was added to the FITCconjugated donkey anti-guinea pig IgG secondary antibody at a 5:1 ratio to diminish the FITC (green) signal to intensities that did not interfere with the visualization of the rhodamine (red) signal. *Apical/luminal regions. Bar, $10 \mu \mathrm{m}$. C: 2-color staining of cells for PRL (green) and actin microfilaments (red) indicates a punctate distribution for PRL largely distinct from the punctate distribution of rab3D. *Apical/luminal regions. Bar, $10 \mu \mathrm{m} . D$ : 2-color staining of cells for rab3D (green) and actin microfilaments (red) confirms that transduction with AdPRL dispersed rab3D away from its normal concentration in the apical cytoplasm. *Apical/luminal regions. Bar, $10 \mu \mathrm{m}$. Two-color staining for PRL and rab3D of cells that had been exposed to elevated levels of PRL in the ambient medium indicated that the cells internalized PRL that had been released from AdPRL-transduced cells in microporous culture inserts or expressed heterologously and added to the medium. In both cases, elevated PRL dispersed rab3D away from its normal concentration in the apical cytoplasm. rPRL, rabbit PRL.

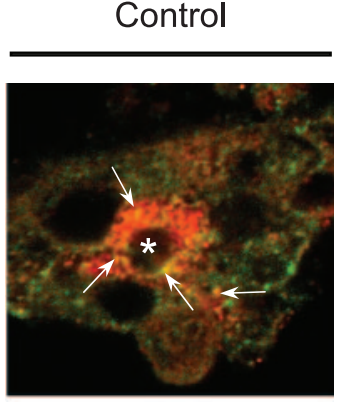

\section{B}
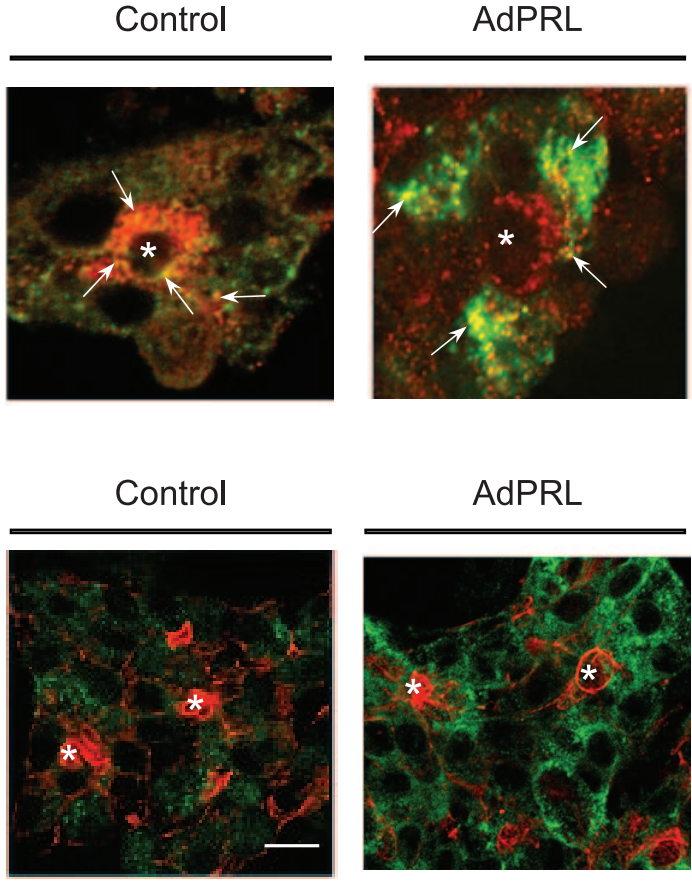

C
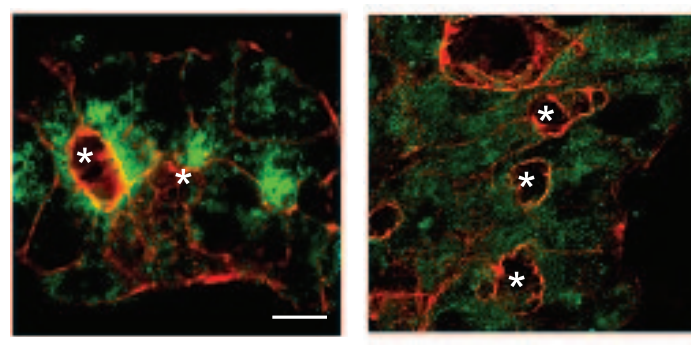

AdPRL

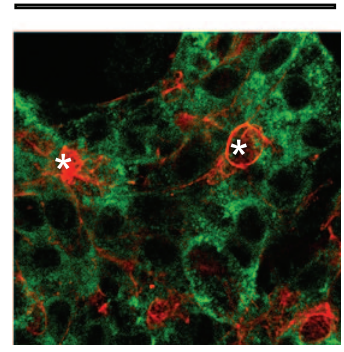

D

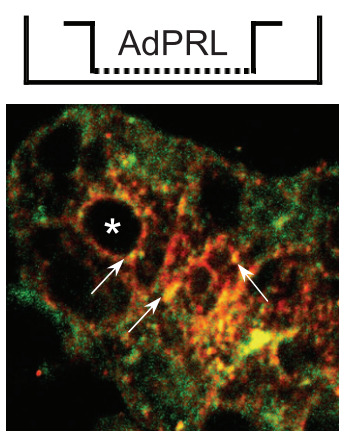

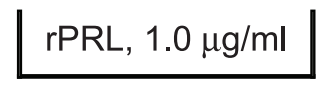

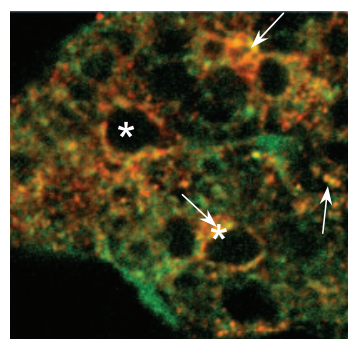

vesicles (Fig. 4A), was tested. This analysis indicated that relatively little of the PRL colocalized with rab3D in merocrine secretory vesicles, which are clearly concentrated in the apical cytoplasm in nontransduced cells (Fig. 4A, left, arrows) as well as in AdLacZ-transduced cells (data not shown). Analysis of the rab3D localization in AdPRL-transduced cells suggested that rab3D had dispersed to a punctate distribution throughout the cytoplasm and that some colocalization of PRL and rab3D occurred in these vesicles (Fig. 4A, right, arrows). The AdPRLinduced dispersal of rab3D from the apical cytoplasm was confirmed by additional analyses in which cells were dually stained for rab3D and actin microfilaments (Fig. 4C).

It was not clear whether the profound dispersal of rab3D induced by AdPRL transduction was limited to cells that had been successfully transduced or whether it also occurred in nontransduced cells that were influenced by secreted PRL present in the ambient medium. In coculture experiments performed to test these questions, AdPRL-transduced cells were placed in microporous inserts above nontransduced cells. As illustrated in Fig. 4D, left, rab3D assumed a dispersed, punctate distribution in both nontransduced and transduced cells, indicating that PRL alters the targeting of secretory vesicles by acting as paracrine mediator and hormone as well as by acting as an intracrine mediator.

To determine whether physiological levels of circulating PRL might alter the targeting of secretory vesicles, parallel experiments were performed in which nontransduced cells were maintained in media supplemented with purified recom- 
binant rabbit PRL at concentrations of 0.4 and $1.0 \mu \mathrm{g} / \mathrm{ml}$. The images in Fig. $4 D$, center and right, demonstrate that both rabbit PRL concentrations caused dispersals of the rab3Dlabeled vesicles similar to the dispersals noted after transduction with AdPRL.

The images in Fig. $4 D$ reveal that, when acinar cells were maintained in the presence of elevated ambient concentrations of PRL, they accumulated PRL immunoreactivity. Nontransduced cells that had taken up PRL and AdPRL-transduced cells exhibited similar subcellular distributions of PRL immunoreactivity and similar colocalizations of PRL with rab3D (compare with Fig. $4 B$, right). Analyses of the colocalizations of PRL with other intracellular markers substantiate this interpretation (42).

Recruitable secretory transport vesicles. Since PRL overexpression so drastically altered the classic regulated secretory pathway but did not alter the temporal characteristics of CChstimulated $\beta$-hexosaminidase secretion (Fig. 3), it was necessary to consider the hypothesis that PRL overexpression enhanced the recruitable secretory transport vesicle pathway such that the CCh-dependent components of both PRL secretion and $\beta$-hexosaminidase secretion mediated by RSTV pathway were increased in compensation for decreased fluxes through the classical regulated secretory pathway. RSTV traffic is driven by the microtubule-based molecular motor cytoplasmic dynein, which associates with vesicle membranes and microtubules through the dynactin complex. $\mathrm{p} 150^{\text {Glued }}$ is a component of the dynactin complex that gives an especially robust immunofluorescent signal in rabbit lacrimal acinar cells. The images in Fig. 5 suggest that neither AdLacZ nor AdPRL transduction markedly altered $\mathrm{CCh}$-induced recruitment of $\mathrm{p} 150^{\text {Glued }}$ to the apical cytoplasm. Similarly, transduction also failed to significantly alter CCh-induced redistributions of vesicle-associated membrane protein-2 (VAMP2), a marker for RSTV (data not shown). Moreover, there was no significant colocalization of PRL with VAMP2.

PRL-induced secretory vesicles. Since AdPRL-transduction appeared not to significantly enhance the RSTV pathway, it was necessary to consider the competing hypothesis that PRL overexpression caused secretory proteins to be redirected from an apically-oriented pathway to a basal-laterally-oriented pathway. Jerdeva et al. (18) have demonstrated that, when rabbit lacrimal acinar cells are transduced with an adenovirus vector for the chimeric secretory protein construct, syncollin-GFP, the product is targeted to mature secretory vesicles. Confocal fluorescence microscopy confirmed that GFP fluorescence was concentrated in large vesicles preferentially located in the apical cytoplasm (Fig. 6A, arrowheads) in cells that had been cotransduced with AdSync-GFP and AdLacZ. In contrast, in cells that had been cotransduced with AdSyn-GFP and AdPRL, the large GFP-containing vesicles were preferentially located in the basal-lateral cytoplasm (Fig. 6A, arrows). Visual scoring of syncollin-GFP labeling in defined regions of cytoplasm in single confocal sections optimized for resolution of lumenal actin (Fig. 6B) indicated that syncollin-GFP was polarized toward the apical cytoplasm in a 3:1 ratio in AdLacZ-cotransduced cells and toward the basal-lateral cytoplasm in 1:2 ratio in AdPRL-cotransduced cells. Stimulation with CCh did not significantly change the apical/basal-lateral polarization in AdLacZ-cotransduced cells after $20 \mathrm{~min}$. In contrast, CCh caused a small but significant decrease in the fraction of vesicles located in the basal-lateral cytoplasm of AdPRL-
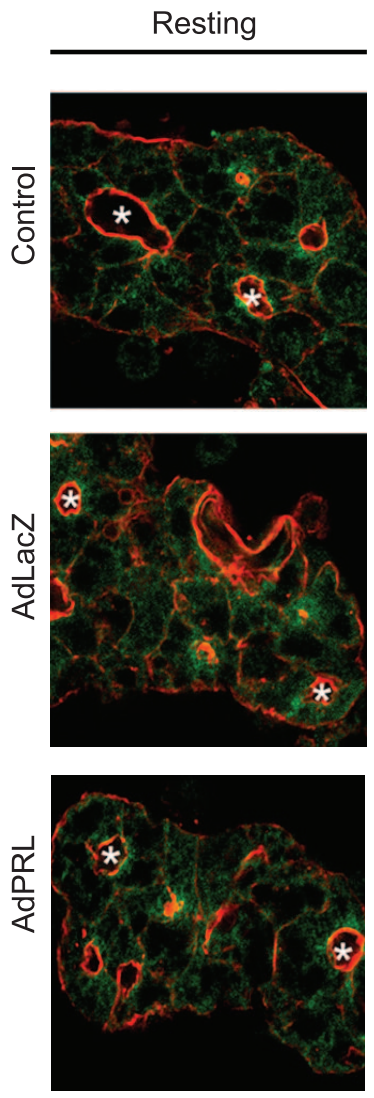
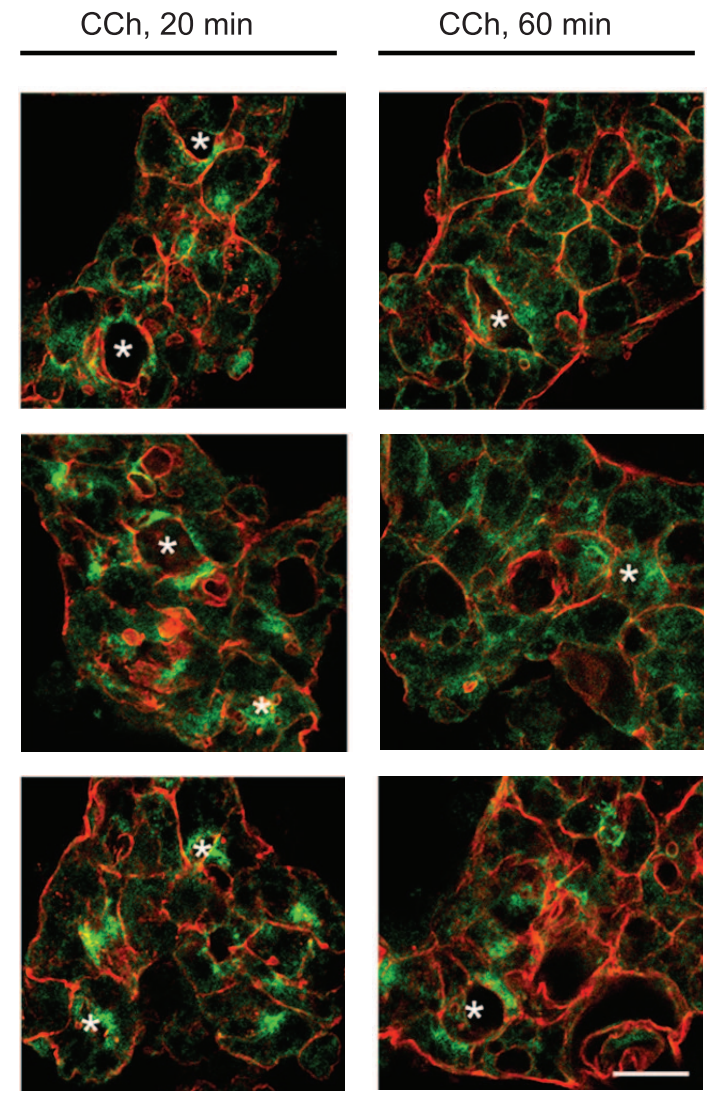

Fig. 5. CCh-induced changes in localization of the dynactin component $\mathrm{p} 150^{\text {Glued }}$. Confocal fluorescence microscopy of cells incubated with or without $100 \mu \mathrm{M} \mathrm{CCh}$ for 20 or 60 min and stained for $\mathrm{p} 150^{\mathrm{Glued}}$ (green) and actin microfilaments (red) indicated that neither AdLacZ nor AdPRL interfered with CCh-induced mobilization of $\mathrm{p} 150^{\text {Glued }}$ to the apical cytoplasm. *Acinar lumina. Bar, $10 \mu \mathrm{m}$. 
A

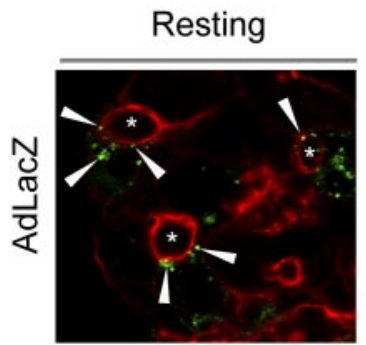

CCh, $20 \mathrm{~min}$
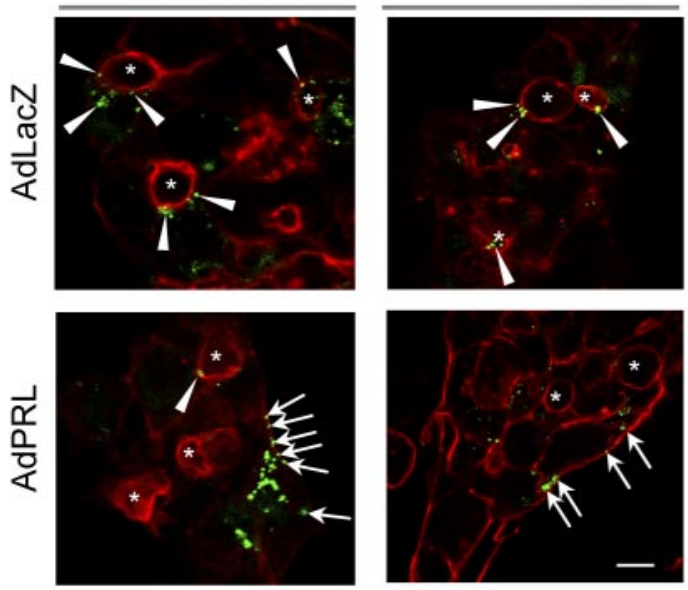

B
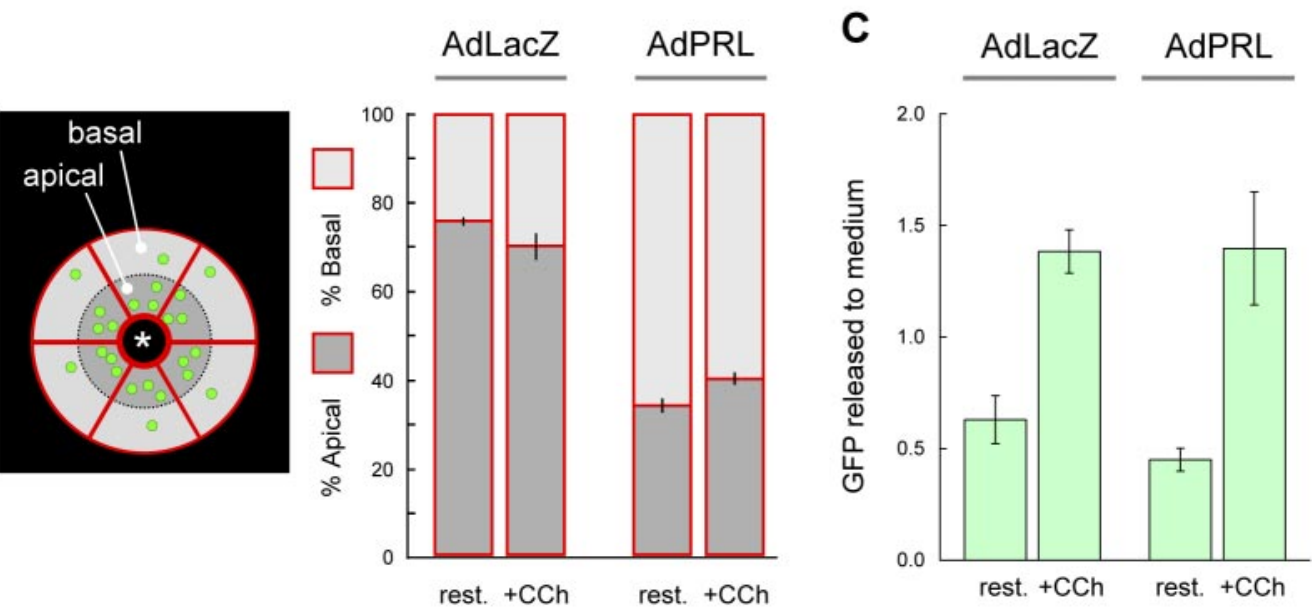

D

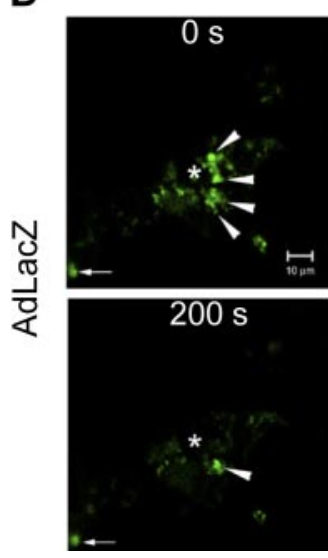

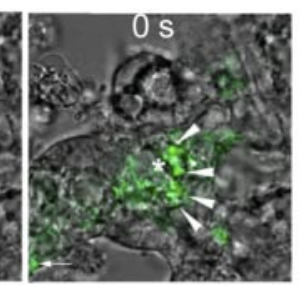
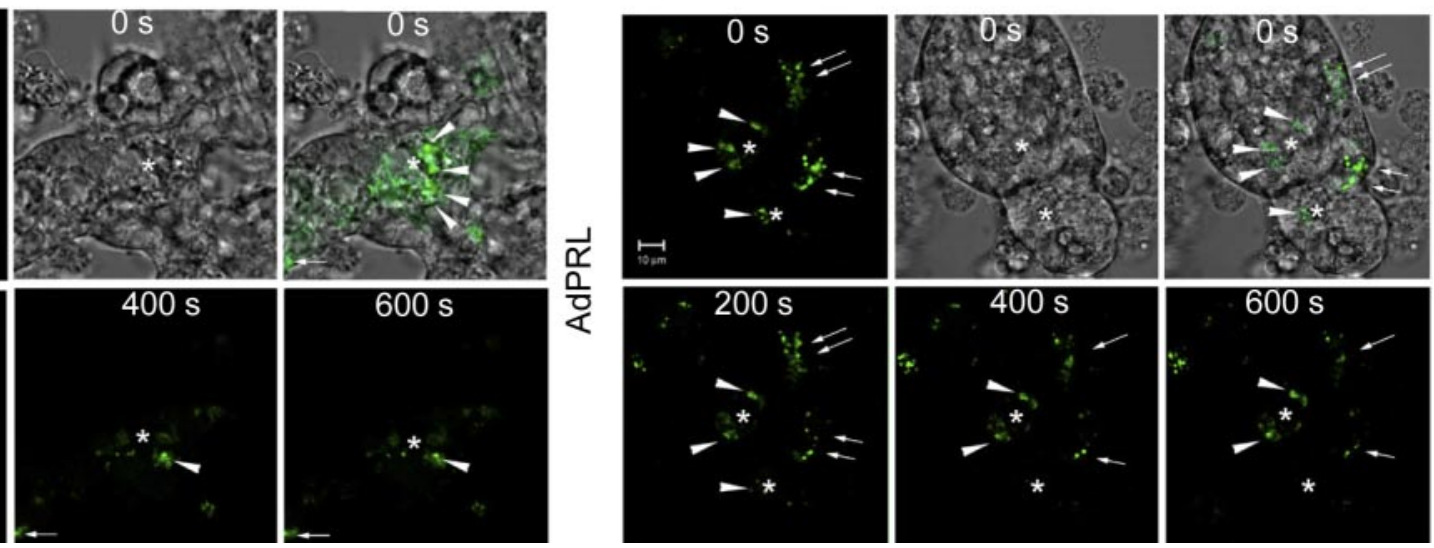

Fig. 6. Effect of PRL overexpression on subcellular localization, CCh-induced intracellular traffic, and secretion of syncollin-GFP. A: acini cotransduced with AdLacZ and AdSync-GFP or AdPRL and AdSync-GFP after 20-min incubation with and without $100 \mu \mathrm{M} \mathrm{CCh}$, fixation, permeabilization, and staining for actin microfilaments (red). In cells cotransduced with AdLacZ, syncollin-GFP-containing vesicles appear to be located primarily in the apical cytoplasm and to be mobilized to the apical plasma membrane in response to stimulation with CCh. Cotransduction with AdPRL appears to have caused syncollin-GFP-containing vesicles to localize primarily in the basal cytoplasm and to be mobilized to the basal-lateral membrane in response to CCh. *Acinar lumena. Bar, $10 \mu \mathrm{m}$. $B$ : scoring of syncollin-GFP localization in experiments described in A confirms that transduction with AdPRL caused syncollin-GFP to be redistributed from the apical to the basal cytoplasm. Syncollin-GFP labeling was scored in 180 resting AdLacZ-transduced cells, 230 CCh-stimulated AdLacZ-transduced cells, 205 resting AdPRL-transduced cells, and $175 \mathrm{CCh}$-stimulated AdPRL-transduced cells from 3 separate preparations. $C$ : secretion of syncollin-GFP from cells that had been cotransduced with either AdLacZ or AdPRL. Analysis of Western blot signals indicates that, whereas transduction with AdPRL reversed the polarity of the syncollin-GFP subcellular distribution, it had no effect on basal- or CCh-stimulated secretion. D: time lapse confocal fluorescence and DIC microscopy of AdSync-GFP-transduced acini shows CCh-induced mobilization of secretory vesicles to the apical membrane in cells cotransduced with AdLacZ and to the basal-lateral membrane in cells cotransduced with AdPRL. *Acinar lumina. Bar, $10 \mu \mathrm{m}$. 
cotransduced cells, suggesting that stimulation might have preferentially mobilized syncollin-GFP-containing vesicles from the basal, rather than the apical, cytoplasm.

Determination of the amounts of syncollin-GFP in the supernatant culture media confirmed that both AdLacZ-cotransduced cells and AdPRL-cotransduced cells secreted it in response to stimulation with CCh (Fig. 6C). Moreover, PRL overexpression had no significant effect on the amounts secreted either in the absence or in the presence of $\mathrm{CCh}$.

Time lapse confocal fluorescent and DIC imaging of live cells, illustrated in Fig. $6 D$, demonstrated that CCh triggered fusion of syncollin-GFP-containing vesicles with the basallateral plasma membrane in AdPRL-cotransduced cells, whereas exocytosis was directed normally, i.e., toward the apical plasma membrane, in AdLacZ-cotransduced cells. (video files of AdSync-GFP-AdLacZ-cotransduced and AdSync-GFP-AdPRL-cotransduced cells before and after CCh stimulation are available in the online version of this article at http://ajpendo.physiology.org/cgi/content/full/00381.2006/DC1).

Since both PRL and syncollin-GFP are secreted in response to $\mathrm{CCh}$ stimulation, the question arose as to whether the CCh-mediated components of both processes are mediated by the same population of vesicles. There was no detectable colocalization of PRL with syncollin-GFP in cells that had been cotransduced with AdLacZ (Fig. 7). However, in cells that had been cotransduced with AdPRL, syncollin-GFP was colocalized in some, but not all, of the basal-lateral vesicles containing overexpressed PRL (Fig. 7).

\section{DISCUSSION}

A cellular model for endomembrane compartmental organization and traffic in lacrimal acinar cells is presented in Fig. 8. Key features of the endosomal traffic pathways were established through studies of the traffic of ${ }^{125}$ I-labeled epidermal growth factor, which acinar cells internalize by receptor-mediated endocytosis and traffic in a biphasic manner, first to the recycling endosome and then to the prelysosome and lysosome (48), and of ${ }^{125}$ I-BSA, which acinar cells internalize by fluid phase endocytosis and traffic primarily to the late endosome, prelysosome, and lysosome (32). The classic regulated secretory pathway has been examined most recently in studies of the stimulation-induced dynamics of actin-GFP (17) and traffic of syncollin-GFP (18). The secretory transport vesicle-mediated pathway has been examined in studies of the traffic of rab3D, cytoplasmic dynein, and $\mathrm{p} 150^{\text {Glued }}$ (41).

Under normal circumstances, mature secretory vesicles, which are prominently marked by the exocytic effector rab3D, are concentrated in the apical cytoplasm. Acute CCh stimulation causes rab3D to redistribute to the cytosol, whereas vesicles either fuse with the apical plasma membrane or undergo homotypic fusion, exocytosing their contents into the fluid forming in the lumen of the acinus-duct network. The observations reported herein indicate that elevated PRL levels cause rab3D to disperse throughout the cytoplasm, where it continues to exhibit a punctate pattern expected for a localization to one or more vesicular compartments. Elevated PRL also alters the distribution of syncollin-GFP. In control cells syncollin-GFP is concentrated in the apical cytoplasm; in the presence of elevated PRL it is concentrated in the basal cytoplasm. The same pattern is observed in cells that have been
A

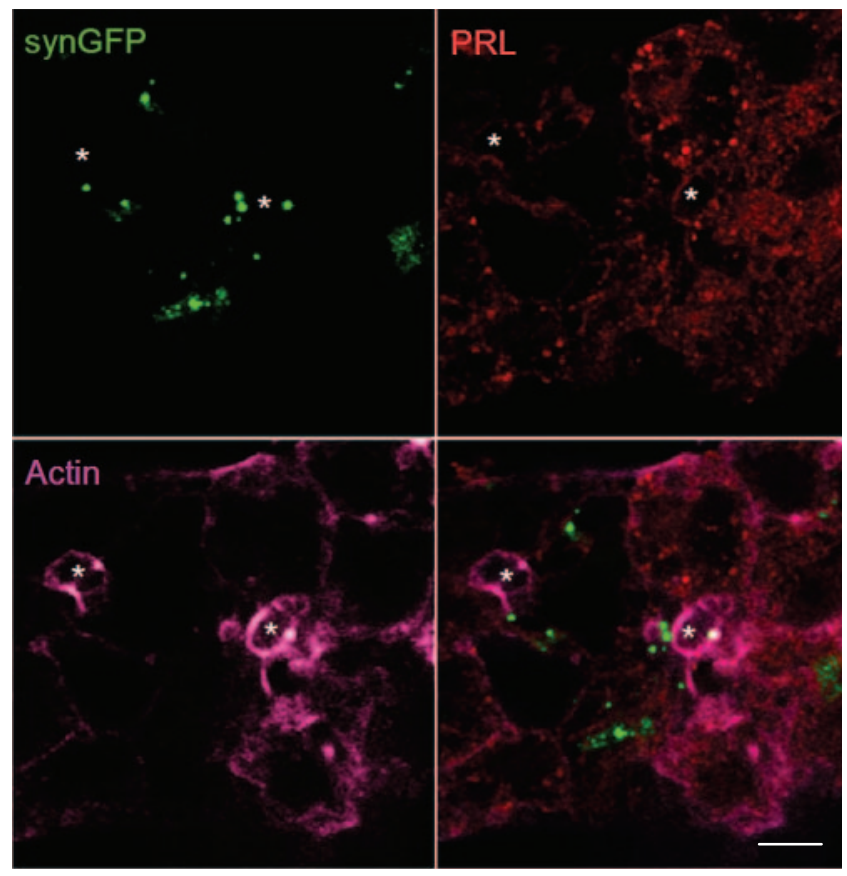

B

AdSyn GFP + AdPRL
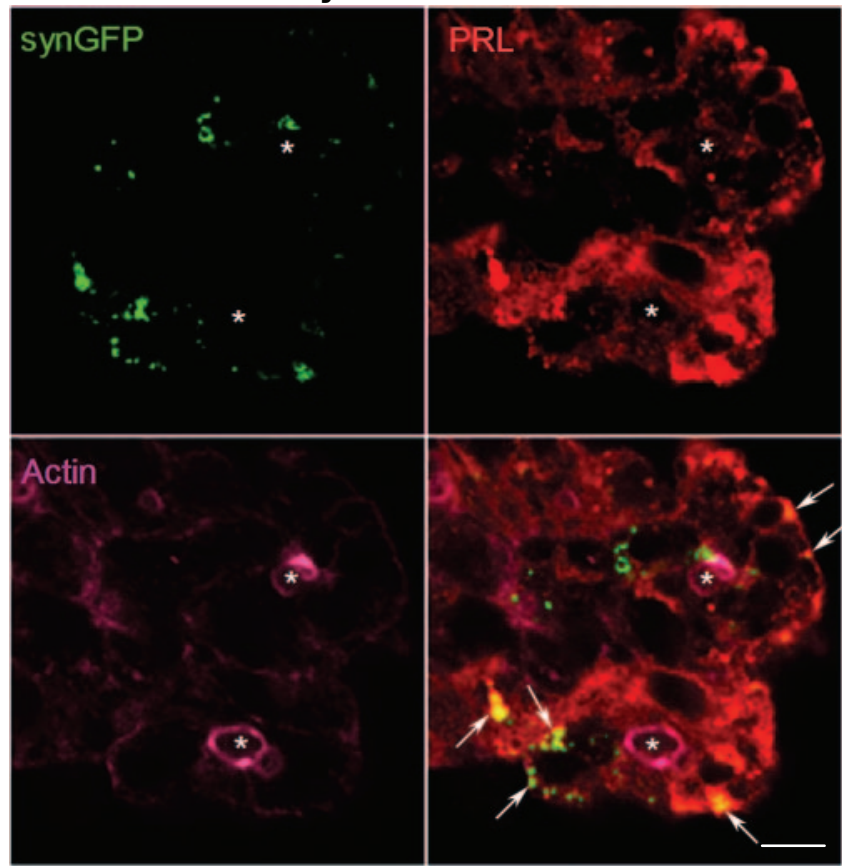

Fig. 7. Three-color imaging of PRL and syncollin-GFP (synGFP) in duallytransduced cells. AdSync-GFP-transduced cells cotransduced with AdLacZ or AdPRL and stained for PRL (red) and actin microfilaments (pink). Arrows indicate colocalization of PRL and GFP in cells cotransduced with AdPRL. *Acinar lumina. Bar, $10 \mu \mathrm{m}$.

transduced with AdPRL, where PRL may act as an intracrine or autocrine mediator, and in cells that have been cultured in media containing elevated levels of PRL. Moreover, in both cases, portions of the PRL colocalize with syncollin-GFP in the basal cytoplasm, and acute stimulation with CCh causes syncollin-GFP-containing vesicles to exocytose their contents at 
Fig. 8. Cellular model for effects of PRL overexpression on the classic regulated secretory pathway. The elements of the model for intracellular compartmental organization and traffic have been described in several recent publications. As in other exocrine cells, mature secretory vesicles (msv) accumulate in the apical cytoplasm; some msv fuse with the apical plasma membrane in response to acute stimulation with CCh. PRL overexpression causes vesicles that contain secretory proteins to disperse throughout the cytoplasm. PRL itself is targeted to both the secretory vesicles and to the early endosome (early end.), recycling endosome (recyc. end.), and terminal transcytotic vesicles (ttv) that constitutively secrete it. When PRL-overexpressing cells are acutely stimulated with $\mathrm{CCh}$, vesicles containing secretory proteins and PRL fuse with the basal-lateral membrane, releasing their contents to the underlying tissue space.

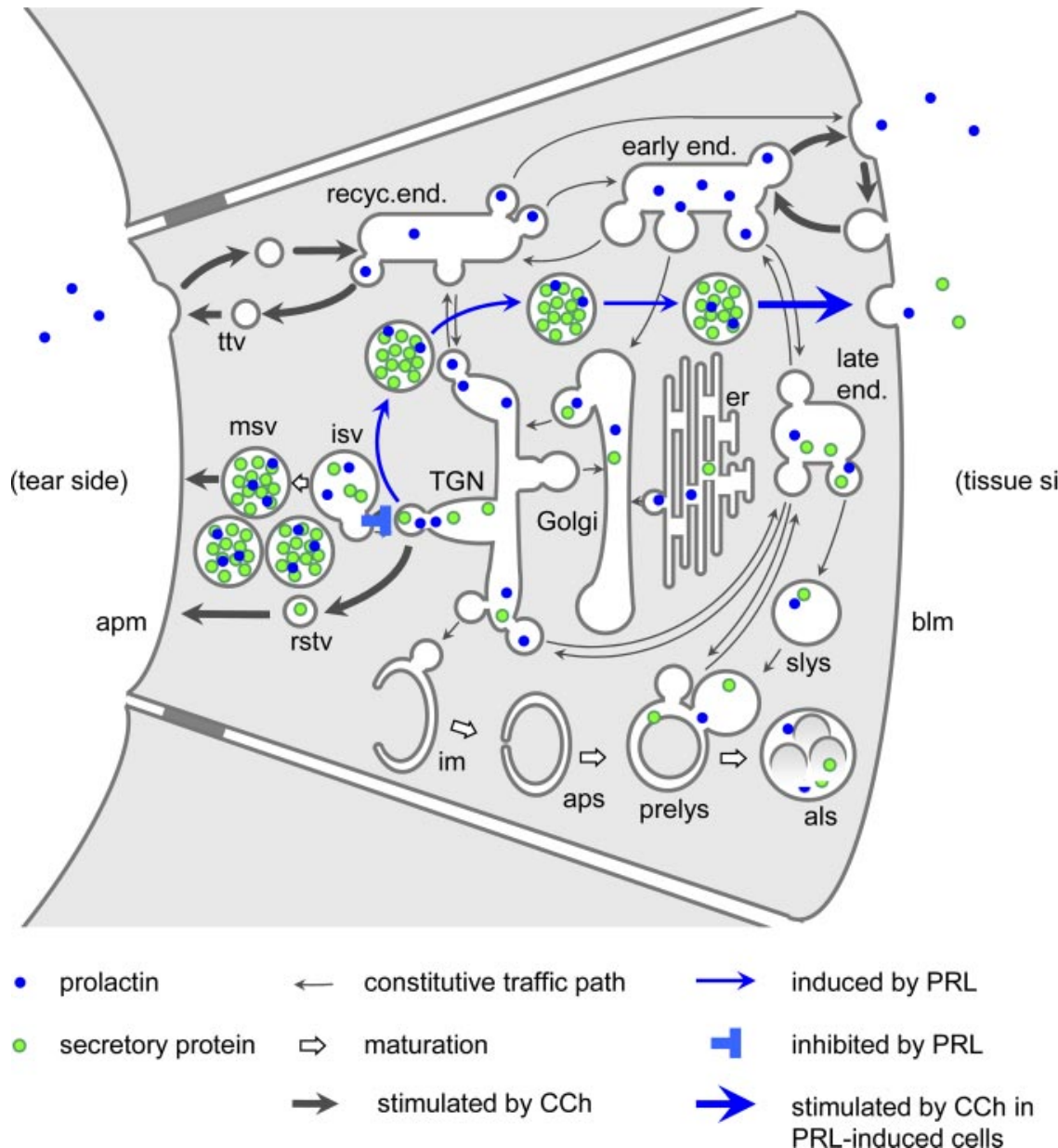

PRL-induced cells the basal-lateral, rather than the apical, plasma membrane. Elevated PRL does not alter the amounts of syncollin-GFP or $\beta$-hexosaminidase that acinar cells secrete under either resting or CCh-stimulated conditions, but it reverses the direction of protein secretion. These phenomena suggest that elevated PRL induces ex vivo lacrimal epithelial cell models to undergo a transformation from their classic exocrine phenotype to an endocrine phenotype reminiscent of that expressed by enteroendocrine cells. Ductal epithelial cells appear to undergo a corresponding phenotypic transformation during pregnancy, when the polarity of the cytoplasmic PRL distribution reverses from apically oriented to basal-laterally oriented. PRL-mediated induction of this phenotypic transformation may reasonably be proposed to account for the decreases in the protein and PRL concentrations of pilocarpine-induced lacrimal gland fluid that occur during pregnancy (9).

Lacrimal acinar cells secrete PRL under resting conditions, and the amount of secretion increases in response to stimulation with $\mathrm{CCh}$. The disparity between the relative $\mathrm{CCh}$-induced increases in PRL secretion (6-fold) and $\beta$-hexosaminidase secretion (14-fold) suggest that relatively greater amounts of PRL are secreted by way of a constitutive pathway. A working hypothesis implicit in the cellular model in Fig. 8 is that the TGN dually targets PRL to populations of transport vesicles that traffic to the immature secretory vesicle and to the early and recycling endosomes; ongoing traffic to the endosomes then supports constitutive exocytic secretion at both the apical and the basal-lateral plasma membranes. In accord with this hypothesis, the data indicate that the compartmental distributions of PRL are similar in control and AdPRL-transduced cells and largely different from the distributions of rab3D, p150 Glued, and syncollin-GFP. These observations suggest that the endosomal traffic of PRL is not an artifact of overexpressed PRL overwhelming TGN sorting mechanisms and spilling over to endosome-bound transport vesicles. When PRL induces lacrimal acinar cells to express an endocrine phenotype, it is itself secreted by way of the induced regulated pathway as well as by way of the parallel constitutive pathway.

It may be fruitful in future studies to explore the possibility that elevated levels of PRL have important implications for the maintenance of tolerance to autoantigens in the lacrimal glands. Proteins that are destined to function in the lysosome follow the common biosynthetic pathway from the endoplasmic reticulum to the TGN, when the lysosomal proteins are targeted to the late endosome, both directly and by way of the early and recycling endosomes. Other work (32) establishes that this traffic is sensitive to the signaling milieu. Chronic stimulation with $10 \mu \mathrm{M}$ CCh blocks movement to the late endosome from both the TGN and the early endosome, with the consequence that catalytically active lysosomal proteases accumulate in the TGN, early endosome, recycling endosome, and immature secretory vesicle. Such an event may both increase secretion of constitutive autoantigens and also lead to secretion of autoantigens that normally are cryptic $(25,32)$. 
Therefore, it is plausible to consider the hypothesis that increased PRL alters the endomembrane traffic and secretion of autoantigens, since it redirects protein secretion from the apical to the basal-lateral plasma membrane.

PRL functions as an intracrine/autocrine mediator and paracrine mediator in a wide variety of tissues, and it elicits a remarkable diversity of responses. In the immune system, PRL stimulates $\mathrm{T}$ and $\mathrm{B}$ cell proliferation, suppresses lymphocyte apoptosis (21), and influences expression of the $\mathrm{T}$ cell effector phenotype $(3,4,6,15,23)$. In the mammary gland and the prostate, PRL supports both epithelial proliferation and expression of differentiated functions. In the mammary gland these functions include expression of polymeric immunoglobulin receptors (pIgR), homing of $\operatorname{Ig} \mathrm{A}^{+}$plasmablasts, differentiation of plasma blasts to plasmacytes, and survival of plasmacytes (30, 31, 46).

A preliminary study (26) indicates that the number of $\operatorname{Ig} \mathrm{A}^{+}$ $B$ cells and plasmablasts infiltrating the lacrimal gland increases during pregnancy. Accordingly, the marked transformation of lacrimal gland immunoarchitecture that occurs during pregnancy and lactation $(9,37)$ may be histological manifestations of an increased capacity to secrete $\operatorname{IgA}$ into the nascent lacrimal gland fluid. The increased amount of PRL that lacrimal epithelial cells deliver to the local milieu may constitute a paracrine signal that orchestrates this immunophysiological transformation.

\section{GRANTS}

This work was supported by National Institutes of Health Grants EY013720 and EY-005801 (A. K. Mircheff); EY-011386 (S. F. Hamm-Alvarez); EY-010550 (J. E. Schechter); EY-012689 and a Core Grant (M. D. Trousdale); DK-048522 (S. F. Hamm-Alvarez and A. K. Mircheff); and California Breast Cancer Research Program Grant 10PB-0127 (A. M. Walker).

\section{REFERENCES}

1. Azzarolo AM, Bjerrum K, Maves CA, Becker L, Wood RL, Mircheff AK, Warren DW. Hypophysectomy-induced regression of female rat lacrimal glands: partial restoration and maintenance by dihydro-testosterone and prolactin. Invest Ophthalmol Vis Sci 36: 216-226, 1995.

2. Azzarolo AM, Mircheff AK, Kaswan RL, Stanczyk FZ, Gentschein E, Becker L, Nassir B, Warren DW. Androgen support of lacrimal gland function. Endocrine 6: 39-45, 1997.

3. Bole-Feysot C, Goffin V, Edery M, Binart N, Kelly PA. Prolactin (PRL) and its receptor: actions, signal transduction pathways and phenotypes observed in PRL receptor knockout mice. Endocr Rev 19: 225-268, 1998.

4. Buckley AR. Prolactin, a lymphocyte growth and survival factor. Lupus 10: 684-690, 2001.

5. Casbon AJ, Warren DW, Mircheff AK. Prolactin inhibits carbacholdependent secretion by lacrimal acinar cells in vitro. Adv Exp Med Biol 506: 231-235, 2002.

6. Corbacho AM, Valacchi G, Kubala L, Olano-Martin E, Schock BC, Kenny TP, Cross CE. Tissue-specific gene expression of prolactin receptor in the acute phase response induced by lipopolysaccharides. Am J Physiol Endocrinol Metab 287: E750-E757, 2004.

7. Cornell-Bell AH, Sullivan DA, Allansmith MR. Gender-related differences in the morphology of the lacrimal gland. Invest Ophthalmol Vis Sci 26: $1170-1175,1985$

8. Damato BE, Allan D, Murray SB, Lee WR. Senile atrophy of the human lacrimal gland: the contribution of chronic inflammatory disease. $\mathrm{Br} J$ Ophthalmol 68: 674-680, 1984.

9. Ding C, Chang N, Fong YC, Wang Y, Trousdale MD, Mircheff AK, Schechter JE. Interacting influences of pregnancy and corneal injury on rabbit lacrimal gland immunoarchitecture and function. Invest Ophthalmol Vis Sci 47: 1368-1375, 2006.

10. Ding C, Wang Y, Zhu Z, Wong J, Yiu S, Mircheff A, Schechter J. Pregnancy and the lacrimal gland: Where have all the hormones gone (Abstract)? Invest Ophthalmol Vis Sci 46: S4406, 2005.
11. Frey WH, Nelson JD, Frick ML, Elde RP. Prolactin immunoreactivity in human tears and lacrimal gland: possible implications for tear production. In: The Preocular Tear Film in Health, Disease, and Contact Lens Wear, edited by Holly FJ. Lubbock, TX: Dry Eye Institute, 1986, p. $798-807$.

12. Gabou L, Boisnard M, Gourdou I, Jammes H, Dulor JP, Djiane J. Cloning of rabbit prolactin cDNA and prolactin gene expression in the rabbit mammary gland. J Mol Endocrinol 16: 27-37, 1996.

13. Gierow JP, Yang T, Bekmezian A, Liu N, Norian JM, Kim SA, Rafisolyman S, Zeng H, Okamoto CT, Wood RL, Mircheff AK. Na-K-ATPase in lacrimal gland acinar cell endosomal system: correcting a case of mistaken identity. Am J Physiol Cell Physiol 271: C1685-C1698, 1996.

14. Hamm-Alvarez SF, da Costa S, Yang T, Wei XH, Gierow P, Mircheff AK. Cholinergic stimulation of lacrimal acinar cells promotes redistribution of membrane associated kinesin and the secretory protein, $\beta$-hexosaminidase, and increases kinesin motor activity. Exp Eye Res 64: 141-156, 1997.

15. Hartmann DP, Holaday JW, Bernton E. Inhibition of lymphocyte proliferation by antibodies to prolactin. FASEB J 3: 2194-2202, 1989.

16. Huang ZM, Zhang J, Azzarolo AM, Mircheff AK, Wood RL, Warren DW. Evidence of expression of prolactin mRNA in male and female rabbit lacrimal glands (Abstract). Invest Ophthalmol Vis Sci 37: S856, 1996.

17. Jerdeva GV, Wu K, Yarber FA, Rhodes CJ, Kalman D, Schechter JE, Hamm-Alvarez SF. Actin and non-muscle myosin II facilitate apical exocytosis of tear proteins in rabbit lacrimal acinar epithelial cells. $J$ Cell Sci 118: 4797-4812, 2005.

18. Jerdeva GV, Yarber FA, Trousdale MD, Rhodes CJ, Okamoto CT, Dartt DA, Hamm-Alvarez SF. Dominant-negative PKC- $\epsilon$ impairs apical actin remodeling in parallel with inhibition of carbachol-stimulated secretion in rabbit lacrimal acini. Am J Physiol Cell Physiol 289: C1052C1068, 2005.

19. Ji Q, Chang L, VanDenBerg D, Stanczyk FZ, Stolz A. Selective reduction of AKR1C2 in prostate cancer and its role in DHT metabolism. Prostate 54: 275-289, 2003.

20. Kratz A, Ferraro M, Sluss PM, Lewandrowski KB. Laboratory reference values. $N$ Engl J Med 351: 1548-1563, 2004.

21. Krishnan N, Thellin O, Buckley DJ, Horseman ND, Buckley AR. Prolactin suppresses glucocorticoid-induced thymocyte apoptosis in vivo. Endocrinol 144: 2101-2110, 2003.

22. Ma L, Bindokas VP, Kuznetsov A, Rhodes C, Hays L, Edwardson JM, Ueda K, Steiner DF, Philpson LH. Direct imaging shows that insulin granule exocytosis occurs by complete vesicle fusion. Proc Natl Acad Sci USA 101: 9266-9271, 2004.

23. Matera L, Mori M, Galetto A. Effect of prolactin on the antigen presenting function of monocyte-derived dendritic cells. Lupus 10: $728-$ 734, 2001.

24. Mathers WD, Stovall D, Lane JA, Zimmerman MB, Johnson S. Menopause and tear function: the influence of prolactin and sex hormones on human tear production. Cornea 17: 353-358, 1998.

25. Mircheff AK, Wang Y, de Saint Jean M, Ding C, Trousdale MD, Hamm-Alvarez SF, Schechter JE. Mucosal immunity and self-tolerance in the ocular surface system. Ocular Surface 3: 14-25, 2005.

26. Mircheff AK, Wang Y, Nakamura T, Ding C, Schechter JE. Enhanced lacrimal gland mucosal immune function associated with pregnancy (Abstract). Invest Ophthalmol Vis Sci 47: S1944, 2006.

27. Mircheff AK, Warren DW, Wood RL. Hormonal support of lacrimal function, primary lacrimal deficiency, autoimmunity, and peripheral tolerance in the lacrimal gland. Ocul Immunol Inflamm 4: 145-172, 1996.

28. Mircheff AK, Warren DW, Wood RL, Tortoriello PJ, Kaswan RL. Prolactin localization, binding, and effects on peroxidase release in rat exorbital lacrimal gland. Invest Ophthalmol Vis Sci 33: 641-650, 1992.

29. Qian L, Wang Y, Xie J, Rose CM, Yang T, Nakamura T, Sandberg M, Zeng H, Schechter JE, Chow RH, Hamm-Alvarez SF, Mircheff AK. Biochemical changes contributing to functional quiescence in lacrimal gland acinar cells after chronic ex vivo exposure to a muscarinic agonist. Scand J Immunol 58: 550-565, 2003.

30. Rincheval-Arnold A, Belair L, Djiane J. Developmental expression of pIgR gene in sheep mammary gland and hormonal regulation. J Dairy Res 69: 13-26, 2002.

31. Rosato R, Jammes H, Belair L, Puissant C, Kraehenbuhl JP, Djiane J. Polymeric-Ig receptor gene expression in rabbit mammary gland during pregnancy and lactation: evolution and hormonal regulation. Mol Cell Endocrinol 110: 81-87, 1995. 
32. Rose CM, Qian L, Hakim L, Wang Y, Jerdeva GY, Marchelletta R, Nakamura T, Hamm-Alvarez SF, Mircheff AK. Accumulation of catalytically active proteases in lacrimal gland acinar cell endosomes during chronic ex vivo muscarinic receptor stimulation. Scand J Immunol 61: 36-50, 2005.

33. Sato EH, Ariga H, Sullivan DA. Impact of androgen therapy in Sjögren's syndrome: hormonal influence on lymphocyte populations and Ia expression in lacrimal glands of MRL/Mp-lpr/lpr mice. Invest Ophthalmol Vis Sci 33: 2537-2545, 1992.

34. Sato EH, Sullivan DA. Comparative influence of steroid hormones and immunosuppressive agents on autoimmune expression in lacrimal glands of a female mouse model of Sjögren's syndrome. Invest Ophthalmol Vis Sci 35: 2632-2642, 1994

35. Schaumberg DA, Buring JE, Sullivan DA, Dana MR. Hormone replacement therapy and dry eye syndrome. JAMA 286: 2114-2119, 2001.

36. Schaumberg DA, Sullivan DA, Buring JE, Dana MR. Prevalence of dry eye syndrome among US women. Am J Ophthalmol 136: 318-326, 2003.

37. Schechter J, Carey J, Wallace M, Wood R. Distribution of growth factors and immune cells are altered in the lacrimal gland during pregnancy and lactation. Exp Eye Res 71: 129-142, 2000.

38. Schechter J, Stevenson D, Chang D, Chang N, Pidgeon M, Nakamura T, Okamoto CT, Trousdale MD, Mircheff AK. Growth of purified lacrimal acinar cells in Matrigel raft cultures. Exp Eye Res 74: 349-360, 2002.

39. Serrander AM, Peek KE. Changes in contact lens comfort related to the menstrual cycle and menopause. J Am Optom Assoc 64: 162-166, 1993.

40. Sullivan DA, Block L, Pena JD. Influence of androgens and pituitary hormones on the structural profile and secretory activity of the lacrimal gland. Acta Ophthalmol Scand 74: 421-435, 1996.

41. Wang Y, Jerdeva G, Yarber FA, da Costa SR, Xie J, Qian L, Rose CM, Mazurek C, Kasahara N, Mircheff AK, Hamm-Alvarez SF.
Cytoplasmic dynein participates in apically-targeted stimulated secretory traffic in primary rabbit lacrimal acinar epithelial cells. J Cell Sci 116: 2051-2065, 2003.

42. Wang Y, Nakamura T, Yarber F, Stevenson D, Trousdale M, HammAlvarez SF, Mircheff AK. Adenoviral vector mediated over-expression of prolactin and its effect on apical secretory pathways in rabbit lacrimal acinar cells (Abstract). Invest Ophthalmol Vis Sci 45: S3876, 2004.

43. Wang Y, Xie J, Yarber FA, Mazurek C, Trousdale MD, MedinaKauwe L, Kasahara N, Hamm-Alvarez SF. Adenoviral capsid modulates secretory compartment organization and function in acinar epithelial cells from rabbit lacrimal gland. Gene Ther 11: 970-981, 2004.

44. Warren DW, Platler BW, Azzarolo AM, Huang ZM, Whang G, Zhang J, Wood RL, Mircheff AK. Pilocarpine stimulates prolactin secretion by rabbit lacrimal glands (Abstract). Invest Ophthalmol Vis Sci 36: S651, 1995.

45. Warren DW. Hormonal influences on the lacrimal gland. Int Ophthalmol Clin 34: 19-25, 1994.

46. Weisz-Carrington P, Roux M, McWilliams M, Phillips-Quagliata JM, Lamm ME. Hormonal influence on the secretory immune system in the mammary gland. Proc Natl Acad Sci USA 75: 2928-2932, 1978.

47. Wood RL, Zhang J, Huang ZM, Gierow JP, Schechter JE, Mircheff AK, Warren DW. Prolactin and prolactin receptors in the lacrimal gland. Exp Eye Res 69: 213-226, 1999.

48. Xie J, Qian L, Wang Y, Rose CM, Yang T, Nakamura T, HammAlvarez SF, Mircheff AK. Novel biphasic traffic of endocytosed EGF to recycling and degradative compartments in lacrimal gland acinar cells. J Cell Physiol 199: 108-125, 2004.

49. Zhu J, Stevenson D, Ritter T, Schechter JE, Mircheff AK, Kaslow HR, Trousdale MD. Expression of IL-10 and TNF-inhibitor genes by lacrimal gland epithelial cells suppresses their ability to stimulate lymphocyte proliferation. Cornea 21: 210-214, 2002.

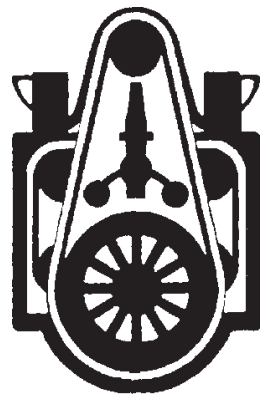

